University of New Hampshire

University of New Hampshire Scholars' Repository

Law Faculty Scholarship

University of New Hampshire - Franklin Pierce

School of Law

$1-1-2014$

\title{
Dietary Supplement Labeling: Cognitive Biases, Market Manipulation \& Consumer Choice
}

\author{
Michael McCann \\ University of New Hampshire School of Law
}

Follow this and additional works at: https://scholars.unh.edu/law_facpub

Part of the Alternative and Complementary Medicine Commons, Consumer Protection Law Commons, Food and Drug Law Commons, Marketing Law Commons, Other Nutrition Commons, and the Pharmacy and Pharmaceutical Sciences Commons

\section{Comments}

Originally published by American Journal of Law \& Medicine. Abstract available at http://papers.ssrn.com/sol3/ papers.cfm?abstract_id $=776864$

\section{Recommended Citation}

Michael McCann, "Dietary Supplement Labeling: Cognitive Biases, Market Manipulation \& Consumer Choice," 31 B. U. AM. J. L. \& MED. 215 (2005).

This Article is brought to you for free and open access by the University of New Hampshire - Franklin Pierce School of Law at University of New Hampshire Scholars' Repository. It has been accepted for inclusion in Law Faculty Scholarship by an authorized administrator of University of New Hampshire Scholars' Repository. For more information, please contact sue.zago@law.unh.edu. 


\title{
Dietary Supplement Labeling: Cognitive Biases, Market Manipulation \& Consumer Choice
}

\author{
Michael A. McCann ${ }^{\dagger}$
}

\section{INTRODUCTION}

There exists increasing concern that the Dietary Supplements Health and Education Act ("DSHEA") has proven ineffective and perhaps counterproductive. Most illustratively, consider a recent and remarkably candid remark from Tommy Thompson, then Secretary of Health and Human Services: "I really think Congress should take a look at the food supplement law again. It doesn't make any sense to me."

A health law that makes no sense to the Secretary of Health of Health and Human Services should certainly draw the attention of academics and policy-makers alike. Much of the debate concerning DSHEA regards the disparity in legislative treatment between dietary supplements, foods, and pharmaceutical drugs. Specifically, while pharmaceutical drugs must undergo years of costly pre-market testing, most dietary supplements-like most foods-can immediately enter the market, and only after repeated instances of adverse reactions can the Food and Drug Administration ("FDA") remove them. Such a framework appears to belie both consumer expectations and marketing strategies, as dietary supplements tend to be most perceived for their apparent medicinal qualities. Similar then to a dangerous street intersection that awaits a tragic accident before town officials install a traffic light, an unsafe dietary supplement awaits a tragic consumer reaction before the FDA may respond. This philosophy of waiting for a foreseeable harm strikes many as unnecessary, inefficient, and perhaps immoral.

On the other hand, many dietary supplements have proven not only safe, but reasonably effective. While significant media attention has been directed toward the minority of instances where dietary supplements have caused harm, less attention

\footnotetext{
Assistant Professor of Law, Mississippi College School of Law; LL.M., Harvard Law School; J.D., University of Virginia School of Law; B.A., Georgetown University. For helpful comments and suggestions, I wish to thank Peter Barton Hutt, Richard Merrill, Mark Josephs, and Marion Nestle. I also wish to thank Fran Miller and the staff of the American Journal of Law \& Medicine for their invitation to participate in this symposium. SSRN author page: http://ssrn.com/author=386163.

See Robert Pear, Departing Health Secretary Warns of Flu Risk and Attacks on Food, N.Y. TIMES, Dec. 3, 2004, available at http://www.nytimes.com/2004/12/03/politics/03cnd-health.html (emphasis added).
} 
has been paid to the more repeated occurrences of either benign or helpful supplements. Moreover, before policy-makers mandate extensive pre-market testing of all dietary supplements, consider the likely effect on production: a certain percentage of dietary supplement makers will find the economics of production too costly and will thus leave the market. Granted, foreign markets for supplements might still provide the requisite incentives for production, but a more costly entrance fee into the U.S. market would clearly deter some level of production and convince a number of makers to leave the market altogether. Equally troubling, companies which choose to remain in the market would presumably pass on a portion of the increased costs to consumers, who often bear the costs of heightened regulation. Consequently, many beneficial dietary supplements would be priced out of the reach of lower and middle income consumers who either have become users of those products or could become users.

The issue then is one of nuance. Rather than sweeping regulatory intervention, perhaps more carefully-tailored alterations would prove most desirable. This philosophy appears desirable given informational deficiencies among dietary supplement consumers, particularly those with cognitive biases that are easily exploited by supplement manufacturers. Promisingly, such deficiencies may be ameliorated through low-cost measures that promote enhanced communication of product characteristics.

For these reasons, this Article proposes a refined approach to dietary supplement labeling that would legally distinguish them on the basis of potential risk and anticipated benefit. Indeed, the existing legal construct of the phrase "dietary supplements" is both curious and overly simplistic. It includes minerals, vitamins, herbs, botanical extracts, and amino acids -in other words, items that are not only functionally different, but which might also present radically different risks and benefits. Along those lines, the very consumers of dietary supplements should be more carefully distinguished. For example, a person who digests Cortislim, a controversial weight-loss supplement containing a murky mixture of vanadium, chromium and botanical extracts, probably subscribes to a different risk and benefit calculation than one who fancies Ricola cough drops. A more calibrated legal framework would recognize those varying calculations.

How might such a revised communicatory model work without precipitating material price increases or deterring beneficial dietary supplement production? One method would entail more carefully-contemplated labeling requirements for dietary supplements. Such requirements should enhance consumer risk-assessment and reward reputable supplement manufacturers. To accomplish these goals, labels should reveal potential interactions with pharmaceutical drugs and other supplements, warnings of over-usage, predictable distinctions between "health" claims and "structure/function" claims, and a recommended intake range based on age and gender, among other personal characteristics. Of similar benefit would be assured ingredient content, as well as greater coordination between the FDA and the Federal Trade Commission ("FTC") in regulating false or misleading dietary supplement claims. Importantly, because such labeling requirements would merely require enhanced informational disclosure, they would impose only minimal cost increases to manufacturing research, development, and production.

A second method would require dietary supplement manufacturers to register ingredient contents with the FDA and to report adverse reactions to all products. These two concepts are related in practice and in form to enhanced labeling disclosure and would remedy a framework whereby the FDA fails to learn of over 99 
percent of adverse consumer reactions and cannot determine the ingredients in nearly one third of those supplements that trigger adverse reactions. Requiring such registration and reporting appears consistent with efficient modeling, particularly given the FDA's limited resources; for the FDA to pursue information already possessed by manufacturers appears wasteful and unnecessary. In addition to providing consumers with more timely and crucial information to use when making consumption choices, such requirements would also enhance lines of communication between the FDA and manufacturers, as industry and governmental actors would share product information. This in turn would enhance the reliability of adverse event reporting and offer promise for greater industry-governmental relations. Moreover, like enhanced labeling, registration and reporting are low-cost, informational directives that preserve the production incentives and pricing schemes of dietary supplement manufacturers.

Imposing such informational duties on dietary supplement manufacturing would enhance consumer information, as well as the level of informed risk and assessable benefit. Moreover, by avoiding incentive-altering regulation, such as pre-market testing of dietary supplements, production incentives would remain intact, particularly for those who sell verifiable products. Prices for such products should also remain within reach of current and future clientele. In addition, by calibrating dietary supplement information, consumer confidence in the much-maligned dietary supplement industry should rise, thus offering a corresponding benefit to manufacturers. Better informed consumers and more legitimized products would also supply manufacturers with additional protection from product liability claims.

In exploring these ideas, this Article will canvass the dietary supplement industry and explore how consumers of dietary supplements often experience deleterious consequences of cognitive biases, particularly those manipulated by manufacturers. At the same time, this Article will identify consumer benefits derived from dietary supplement consumption, even when such benefits cannot be "clinically" validated. This Article will also examine the salience of legislative choice in promulgating dietary supplement laws, especially as it pertains to communication of risk and benefit. In doing so, this Article will incorporate a comparative approach, including a comparison to European models of consumerism in the dietary supplements context. Lastly, this Article will examine the prescription of new informational duties for dietary supplement manufacturers and how such duties might enhance consumer choice without deterring production.

\section{THE DIETARY SUPPLEMENT MARKET \& ITS INTERACTION WITH CONSUMER RISK}

\section{A. EXPloring THE DieTARY SUPPlEMENT MaRKET}

The term "dietary supplement" comprises a strikingly large and diverse class of products under one convenient rubric. Consider a working list of dietary supplements compiled by the FDA: vitamins, essential minerals, protein, amino acids, herbs, animal and plant extracts (e.g., garlic extracts and inert glandulars), fats and lipid substances (e.g., fish oils, sterols, and essential fatty acids), dietary fibers, and chemical compounds that may have biological activity but that are generally not recognized as nutrients under the traditional definition of that term (e.g., 
bioflavonoids, enzymes, nucleic acids, para-aminobenzoic acid, and rutin). ${ }^{2}$ Together, these and other substances comprise the nearly 29,000 dietary supplements available for sale in the United States. ${ }^{3}$

Dietary supplements are distributed in a variety of instruments, most often capsules, tablets, liquids, or powders. ${ }^{4}$ For this reason, some resemble medicines, particularly when packaged in containers that indicate expiration dates or lot numbers or that utilize cotton fillers, tamper proof caps, and other suggestive characteristics. ${ }^{5}$ Moreover, given the abundance of dietary supplement products, many appear similar in packaging but offer disparate functions, risks, and benefits. ${ }^{6}$

The dietary supplement industry has more than quadrupled in size since the passage of DSHEA in 1994. More specifically, the industry recorded $\$ 20.1$ billion in sales in $2003,{ }^{7}$ up from $\$ 18.8$ billion in $2002^{8}$ and $\$ 17.8$ billion in $2001 .^{9}$ In fact, industry sales have appreciated over 400 percent from $\$ 4$ billion in $1994 .^{10}$ Moreover, to place the $\$ 20.1$ billion dietary supplement industry sales figure in perspective, consider the following industry sales figures, also from 2003: candy industry ( $\$ 1.99$ billion $) ;{ }^{11}$ videogame industry $(\$ 10.0$ billion $) ;^{12}$ organic food industry ( $\$ 10.8$ billion); ${ }^{13}$ toy industry ( $\$ 20.7$ billion); ${ }^{14}$ and the restaurant industry ( $\$ 440.1$ billion). ${ }^{15}$ Absent significant regulatory changes, the dietary supplement industry anticipates continued, high-rate growth for an indefinite period of time. ${ }^{16}$

2 Regulation of Dietary Supplements, 58 Fed. Reg. 33,690, 33,692 (proposed June 18, 1993) (to be codified at 21 C.F.R. Ch. I).

${ }_{3}$ See Adverse Events Associated with Dietary Supplements: An Observational Study, 361 LANCET 101 (2003).

4 Other instruments include powders, teas, loose plant parts, and lozenges. Id.

558 Fed. Reg. at 33,692; see also William J. Skinner, Allowable Advertising Claims for Dietary Supplements, 5 J. PHARmaCY \& L. 309, 310 (1994) (noting that labels for homeopathic supplements appear strikingly similar to those for medicinal cold and flu products).

Consumers can easily confuse black or green tea with "dieter's teas" advertised for weight loss. Dieter's teas are considered potentially harmful by the FDA. See Teri Capriotti, Any science Behind the Hype of 'Natural' Dietary Supplements?, 5 MED/SURG NURSING 339 (2004).

7 Herbal Supplements: Studies Show Dangerous Interactions with RX, Drugs, AM. HEALTH LINE, June 23, 2004, available at LEXIS, News Database.

${ }_{8}$ Use of Dietary Supplements by Children: Testimony Before the House Energy and Commerce Comm., Fed. Doc. Clearing House Cong. Testimony, June 16, 2004 (statement of Howard Beales, Director, Bureau of Consumer Protection), available at LEXIS, Nexis Library, CNGTST file [hereinafter Statement of Howard Beales].

Andrea Combs, Dietary Supplements Promise Results, Still Dubious, CBS MaRKeTwatch, May 7, 2003, available at LEXIS, News Library, MKTWTC file.

${ }_{10}$ See Chris Money, Teen herbicide: Dietary Supplements can be Deadly. So Why are They Being Marketed to Kids?, 28 MOTHER JONES, May 1, 2003, at 18.

$11 \quad$ Christine Laue, Sweet Indulgence Some Fear the Accessibility of Candy Around Halloween, but Others See It As Just Part of the Fun, OMAHA World-Herald, Oct. 19, 2004, at $01 \mathrm{E}$.

${ }_{12}$ Elizabeth Leis, Toys are still for Playing, CAPITAL, Dec. 20, 2004, at A1.

13 Andrew Martin, Organic Milk Debate, CHI. TRIB., Jan. 10, 2005, at 1.

14 Leis, supra note 14.

is Robin Davis, Deli Day, Columbus DisPatch, Sept. 29, 2004, at $01 \mathrm{~B}$

16 Julie Deardorff, Sitting Pretty, CHI. TriB., Jan. 25, 2004, at 1 (citing Paul Zane PIlzer, The Wellness REVOLUTION (2004)); see also StockSplits.com Announces 12 to 20 Plus Has Received Approval From Its Shareholders for a 1 for 57 Reverse Split, MARKET WIRE, Nov. 4, 2004, available at LEXIS News Database (projecting that retail sales in the dietary supplement market are expected to reach $\$ 21$ billion by year 2007 , according to Frost \& Sullivan reports). But see Amy Klien, Diet Additive Seller Must Repay Millions, RECORD, July 13, 2004, at Al (noting that recent litigation against dietary supplement manufacturers has damaged the industry's reputation). 
On the other hand, some external observers are skeptical of such anticipated growth, reasoning that recent litigation has irreparably damaged the industry's reputation. $^{17}$

The proportion of Americans using dietary supplements has grown in tandem with surging sales. Indeed, approximately 60 percent of U.S. adults regularly use dietary supplements, a percentage which has escalated considerably since the passage of DSHEA. ${ }^{18}$ Similar growth patterns have also emerged amongst children. $^{19}$

Growing sales and the widening class of dietary supplement consumers have invited inquiry about these products' popularity. Dietary supplements appear attractive for several reasons. Many consumers gravitate to supplements that promise to help them lose weight or "regain lost vigor" without requiring physical exertion or dieting. ${ }^{20}$ Certain supplements can also induce effects similar to prescription medicines but retail without required prescriptions and often at markedly lower prices. ${ }^{21}$ Still other consumers take supplements as substitutes for indigestible foods flush in nutrients; this is especially apparent among persons who cannot digest dairy products. ${ }^{22}$ Moreover, as many as two out of five consumers take vitamin supplements everyday. ${ }^{23}$ There are also consumers who simply prefer holistic and natural products to traditional medicines. Such preferences often reflect individualistic predilections, such as distrust of modern medicine or appreciation of "wholesome" or "earthly" substances. ${ }^{24}$ Similarly, some consumers use supplements for cultural and ethnic practices, ${ }^{25}$ as well as for emotional and psychological needs. ${ }^{26}$

17 See, e.g., id.

FDA Holds Public Meeting About Safety of Dietary Supplements (National Public Radio broadcast, Nov. 15, 2004), available at LEXIS, News Library, NPR file. But see Darshak Sanghavi, $A$ Mainstream Doctor Finds a Place for Alternative Medicine, Boston GLOBE, June 22, 2004, at Cl (citing a study conducted by JAMA, which concluded that 42 percent of Americans use dietary supplements).

19 The market for children's supplements has also been growing. Industry analysts estimate annual sales of children's supplements reached $\$ 510$ million as of July 2002 and represented one of the top niche markets in the supplement industry. Statement of Howard Beales, supra note 8 .

20 For example, Zantrex-3, which includes caffeine, ginseng, and cocoa nut, has become especially popular as a supplement which helps people lose weight and regain energy. Moreover, its popularity has only increased since the FDA banned ephedra. See Carey Hamilton, Ephedra Ban Tilts Diet Pill Market, Salt LaKe TriB., Apr. 26, 2004, at A1.

${ }_{21}$ See, e.g., Melissa Martinez, Often-crippling Arthritis Pain Has Led Many Sufferers on a Search for a Cure, EL PASO TIMES, Mar. 6, 2000, at 1. 1999 , at $\mathrm{S} 13$.

See Holly Weaver Beason, What to Do When Milk Isn't Your Pal, CHI. SUN-TIMES, Oct. 27,

${ }_{23}$ Jennifer Harper, Japanese Find lst New Vitamin in 55 Years, WASH. POST, Apr. 28, 2003, at A03 (citing data the National Health and Nutrition Examination Survey, conducted by the University of Wisconsin in 2001, that about 40 percent of Americans take vitamins regularly); see also Paul L. Geltman et al., Daily Multivitamins With Iron to Prevent Anemia in High-Risk Infants: A Randomized Clinical Trial, 114 PEDIATRICS 86 (2004) (finding that 41 percent of parents give their children vitamins everyday, and 22 percent do so "usually").

24 Paige Hewitt, Focus: Vaccinations, Hous. Chron., July 30, 2003, at A22.

25 See, e.g., Alan R. Clough et al., Liver Function Test Abnormalities in Users of Aqueous Kava Extracts, $6 \mathrm{~J}$. TOXICOLOGY 821 (2003) (explaining that some consumers take Kava in adherence to local cultural practices).

${ }_{26}$ See, e.g., SuperCool St. John Launched for Emotional Well-Being, L. \& HEALTH WEEKLY, Aug. 14, 2004, at 31 (noting that consumers take St. John's Wort to help mood swings). 


\section{B. Comparing Regulation of Dietary Supplements to Pharmaceutical DRUGS \& FOOD}

Compared to drugs, dietary supplements and their labels appear strikingly unregulated. Instead, dietary supplements are regulated more like food products. Specifically, under DSHEA, the controlling legislation, most dietary supplements become available to consumers without FDA review or approval, and in only limited instances do novel ingredients receive pre-market evaluation for safety and efficacy. ${ }^{27}$ Though seemingly benign, this pre-market arrangement proves slightly more arduous than that imposed on food products, which may enter the stream of commerce without FDA approval of specific ingredients, ingredient quantities, or interactions between ingredients. Like food labels, however, dietary supplement labels must list ingredients and levels of vitamins and minerals in a standardized "Supplement Facts" panel. Manufacturers are afforded wide latitude in product labeling and in product promotion; short of egregious misrepresentation or explicit promise to cure disease, supplement manufacturers possess broad autonomy in how they shepherd their product through the American economy. ${ }^{28}$

For those who regard dietary supplements more like drugs than food products, this absence of pre-market testing and stringent labeling requirements reflects a peculiar deviation from norms within the medical and regulatory communities. Indeed, compare dietary supplement regulation to that of pharmaceutical drugs. ${ }^{29}$ Since passage of the Kefauver-Harris Amendment ${ }^{30}$ in 1962, drugs must undergo carefully designed clinical tests before becoming available to American consumers. ${ }^{31}$ Clinical drug testing has been deemed essential to prevent dangerous and inefficacious practices. 32 The "New Drug Application" ("NDA") process is often arduous and costly. Drug manufacturers may wait as long as thirteen years before receiving FDA approval, during which time they may invest as much as $\$ 1.7$ billion in researching and testing. ${ }^{33}$ Even after such investment and wait, an application may be denied for insufficient safety, inadequate testing, poor packaging, deficient manufacturing, and lack of evidence that the drug will achieve its intended effect. ${ }^{34}$ In short, while dietary supplement manufacturers encounter a nearly unfettered path to American consumers, drug manufacturers often travel a lengthy, costly, and uncertain road to reach those same consumers.

27 For extensive analysis of DSHEA, see infra Part III.F.

28 Michael Cohen \& Mary Ruggie, Integrating Complementary and Alternative Medical Therapies in Conventional Medical Settings: Legal Quandaries and Potential Policy Models, 72 U. CIN. L. REV. 671, 716 (2003).

29 Drugs are statutorily defined as "articles intended for use in the diagnosis, cure, mitigation, treatment, or prevention of disease in man or other animals." 21 U.S.C. $\$ 321(\mathrm{~g})(1)(\mathrm{B})(2000)$.

$30 \quad 21$ U.S.C. $\$ 355(2000)$ (also known as the "Drug Efficacy Amendment").

31 For a more detailed discussion regarding the Kefauver-Harris Amendment, see Richard A. Merrill, The Architecture of Government Regulation of Medical Products, 82 VA. L. REV. 1753, 176469 (1996).

${ }_{32}$ See 21 C.F.R. § 312.23(a)(6)(iii)(b) (2004); see also Merrill, supra note 32, at 1782 (detailing clinical guidelines).

${ }^{33}$ See RX Drugs: Development Costs $\$ 1.7$ Billion Per Product, Study Says, Am. Health LINE, Dec. 8, 2003 (citing study conducted by Bain \& Co. in 2003); see also Brian Varstag, Clinical Trials to Receive a Boost, But How Big?, 286 JAMA 1303, 1304 (2001) (assessing the typical cost as $\$ 500$ million); Michael J. Malinowski, Legal Development: Globalization of Biotechnology and the Public Health Challenges Accompanying It, 60 ALB. L. REV. 119, n. 179 (1996) (describing cost structure for testing).

$34 \quad 21$ U.S.C. $\$ 355$. 
A further variance concerns labels. Unlike largely unregulated supplement labels, which often express unrealistic claims and inaccurate content, drug labels are highly scrutinized and thus carefully tailored, resulting in cautions and measured claims. ${ }^{35}$ Indeed, since passage of the Federal Food, Drug and Cosmetic Act of $1938^{36}$ ("FDCA") and subsequent regulations, drug manufacturers must label their products with unambiguous directions and all-inclusive lists of warnings while avoiding promotional language. ${ }^{37}$ The FDCA also requires that the sponsor of a drug verify the safety and efficacy of each claim made in its labeling. ${ }^{38}$ Moreover, drug manufacturers may only market their products for FDA approved uses; ${ }^{39}$ any marketing beyond such uses comprises "off-label" marketing, which the FDCA prohibits. $^{40}$

\section{Cognitive Biases Among Dietary Supplement Consumers \& Market MANIPULATION}

The existing regulatory treatment of dietary supplements has concerned policymakers in recent times, particularly as data has revealed that dietary supplement consumers often perceive their consumption choice as one in lieu of drugs or other medicines. Indeed, a recent study revealed that approximately 80 percent of consumers who use dietary supplements purchase them instead of prescription drugs or over-the-counter drugs. In another study, the two most cited consumer reasons for taking supplements were "to feel better" (72 percent) and "to help prevent getting sick" (67 percent) ${ }^{41}$ Most consumers also assume that dietary supplements are qualitatively better than drugs: According to a third study, 56 percent of consumers believe that supplements offer benefits comparable to those of drugs but with fewer side effects, and 53 percent maintain that supplements often offer benefits that conventional drugs cannot. ${ }^{42}$ Such data comports with the general impression among clinicians that patients increasingly bypass consultations in favor of self-medication through dietary supplements, ${ }^{43}$ as well as with long-standing historical and global patterns of supplement use, particularly of herbs as medicines. ${ }^{44}$

35 See Mara A. Michaels, FDA Regulation of Health Claims under the Nutrition Labeling and Education Act of 1990: A Proposal for a Less Restrictive Scientific Standard, 44 EMORY L.J. 319,328 (1995).

Pub. L. No. 75-717, 52 Stat. 1040 (1938) (current version at 21 U.S.C. $\S \S 301-397$ (2000).

See, e.g., 21 C.F.R. $\S \S 201.56$ (a)-(b) (2004). Prior to enactment of the FDCA, a drug manufacturer could set its own development and marketing schedule. If FDA disputed a drug's safety or effectiveness, the agency bore the burden of initiating the legal process and proving that it was dangerous or mislabeled. See Merrill, supra note 32, at 1797.

38 See id. at 1853 (exemplifying that if a manufacturer wished, implausibly, to market a drug for the treatment of both high blood pressure and diabetes, it would need to submit to FDA sufficient evidence that the drug was safe and effective for each "indication").

39 See id. at 1768.

$40 \quad$ See 21 U.S.C. $\$ \$ 331(a)-(b), 352$ (2000).

41 See New Legislation Introduced to Allow Health Plan Coverage of Dietary Supplements, PR NEWSWIRE, Sept. 4, 2001, available at LEXIS, News Library.

$42 \quad I d$

43 See, e.g., Arthur P. Grollman, professor of pharmacological sciences and medicine at the State University of New York, Regulation of Dietary Drugs is Long Overdue, N.Y. TIMEs, Feb. 23, 2003, at 10 (stating "[h]erbal products are primarily used as medicines"); see also Arnold l Friede, Dietary Supplements: Background for Dialogue Between the Industry and Medical Profession, 53 FOOD DRUG L.J. 413, 419 (1998) (finding that consumers tend to choose self-medication through dietary supplements whenever exposed to new health claims among dietary supplement products).

See Weishi Li, Botanical Drugs: A Future for Herbal Medicines, 19 J. CONTEMP. HEALTH L. \& POL'Y 117, 119 (2002); see also MICHAEL H. COHEN, BEYOND COMPLIMENTARY MEDICINE: 
Therefore, extensive regulatory variances between dietary supplements and drugs appear disconsonant with consumer expectations. ${ }^{45}$

Moreover, dietary supplements are often marketed as medicinal products rather than as food products. ${ }^{46}$ Likewise, supplement manufacturers sometimes obscure distinction between their products and medicines through misleading product names, such as the recently enjoined "Herbrozac," which, like the drug Prozac, claimed to treat clinical depression among children. ${ }^{47}$ Similar concerns have been raised of the supplement "herbal fen-phen," which sounds uncannily similar to the diet drug combination fenfluramine and phentermine, commonly called "fen-phen."

These consumer purchasing patterns and advertising schemes appear even more meaningful when considering that while many of the ingredients in dietary supplements would prove safe in isolated form, certain ingredients may present enhanced danger when offered in high concentrations or in chemical form. ${ }^{49}$ Complicating matters, these ingredients are typically displayed on labels in promotional ways that distort risk. ${ }^{50}$

Legal and Ethical Perspectives on Health Care and Human Evolution (2000) (offering a historical account of supplement usage, including usage as medicines); see also Regulation of Dietary Supplements, 58 Fed. Reg. 33,690, 33,697-98 (proposed June 18, 1993) (finding that herbs have traditionally been used as medicines).

45 Aside from popular recognition of their functional similarity, dietary supplements and medicines have also been regarded as alike by members of Congress. For instance, in 2001, Senators Tom Harkin and Orrin Hatch proposed the Dietary Supplement Tax Fairness Act, legislation that would have amended Section 213(d) of the Internal Revenue Code of 1986, which limits the medical expense deduction to prescribed drugs, to include spending on dietary supplements within the definition of a medical expense. In introducing this legislation, Senator Harkin noted the need for parity, arguing, "Our current policy is unfair and is failing to take full advantage of the potential to improve health and hold down health care costs through preventive health care practices available to consumers. Bringing the code up to date to recognize and allow for this important need for wellness and health promotion is an important step forward to overall sound healthcare policy." See Statements on Introduced Bills and Joint Resolutions, 147 Cong. Rec. S. 8709, Aug. 2, 2001. Also consider similar remarks by Rep. Dan Burton: "Many consumers often ask why there are no insurance benefits for dietary supplements, which are used primarily to maintain good health and wellness. Some dietary supplements, like Folic Acid, can help prevent disease or disease risks like birth defects. Many insurance companies would like to offer coverage to their beneficiaries who continually demand this type of coverage. Unfortunately, the tax code does not allow an insurer to offer this coverage without incurring tax liabilities to consumers and higher administration costs. This powerful disincentive needs to be removed so health insurers can begin developing meaningful and cost effective benefits for their beneficiaries and assist them in maintaining good health longer." See Extension of Remarks by Rep. Burton, 147 Cong. Rec. E. 2288, Dec. 13, 2001.

${ }_{46}$ See Kessler Criticizes Dietary Supplements, OMAHA World-Herald, Mar. 4, 1998, available at LEXIS, News Library (citing remarks by former FDA Commissioner David Kessler, who argued that dietary supplements are often marketed to confuse consumers into believing those products possess medicinal qualities).

${ }_{47}$ See Eli Lilly \& Co. v. Natural Answers, Inc., 233 F.3d 456, (7th Cir. 2000) (affirming enjoining use of defendant's mark under the Lanham Trademark Act, the Federal Trademark Dilution Act and state unfair competition law); see also Liem Thanh Do, Dilution Standard Number: A Quantitative Approach in Proving Actual Dilution under the Federal Trademark Dilution Act, 11 TEX. WESLEYAN L. REV. 107, 128 (2004) (discussing the implications of the Eli Lilly holding).

${ }_{48}$ See Marian Segal, FDA Warns Against Drug Promotion of "Herbal Fen-Phen", FDA TALK PAPER, Nov. 6, 1997, available at http://www.fda.gov/bbs/topics/ANSWERS/ANS00832.html.

49 Regulation of Dietary Supplements, 58 Fed. Reg. 33,690, 33,692 (June 18, 1993); see also, e.g., Bernard A. Schwetz, Safety of Aristolochic Acid, 285 JAMA 2705 (2001) (describing deleterious consequences of aristolochic acid when dispensed in high concentrations).

5058 Fed. Reg. at 33,692; see also Wayne B. Jonas, Alternative Medicine: Learning From the Past, Examining the Present, Advancing to the Future, 280 JAMA 1616, 1618 (1999) (identifying historical trends of dietary supplement labeling that have proved deleterious for consumers). Notably, these phenomena appear exacerbated on the Internet with on-line vendors. See Charles A. Morris \& Jerry Avorn, Internet Marketing of Herbal Products, 290 JAMA 1505, 1509 (2003). 
Promotional concerns appear especially salient for consumers prone to discounting product risk, such as economically-disadvantaged persons and children. These are especially impressionable groups, and thus vulnerable to "myth-making" among dietary supplements, whereby value is ascribed to reputational, rather than scientific qualities. ${ }^{51}$ Indeed, despite the lack of clinical validation, many consumers believe that certain supplements are "proven." 52 For instance, garlic pills are said to lower cholesterol; ginkgo allegedly helps one's memory; and Echinacea may effectively treat flu symptoms. ${ }^{53}$ To date, however, independent research has failed to confirm any of these claims. ${ }^{54}$ Thus, much like superstitions and folklore, dietary supplements often enjoy more salience than objective data would suggest.

Optimism bias, or consumers' tendency to assume that general risks posed by products do not apply with equal force to themselves, ${ }^{55}$ may offer a useful corollary to myth-making. This is especially true since optimism bias tends to flourish when risks are long-term or are presumed modifiable through behavior ${ }^{56}$ Along those lines, when consumers assume that signs of toxicity will appear early in product usage, they tend to assume that an absence of such early signs foretells exemption from future risk. ${ }^{57}$ For instance, smokers tend to perceive smoking as significantly less risky for themselves than for other smokers. ${ }^{58}$ These effects are most pronounced among children smokers, who often rate their own chances of contracting lung disease as nearly identical to those of non-smokers. ${ }^{59}$

Myth-making and optimism bias among consumers are especially exploitable characteristics. Indeed, when consumers systematically underestimate risk, manufacturers may more readily conceal risk information. ${ }^{60}$ Conversely, when positive images of product use repeatedly appear-such as an often-aired infomercial of a slim man and woman consuming a particular diet pill-consumers

51 Elizabeth R. McGuire, The Entitlement of Veterans Affairs Medical Patients to Vulnerable Population Status for Human Medical Research, 2 HEALTH MATRIX 259, 279-80 (1992).

52 See Doug Cutter, The 7 Myths of Dietary Supplements, RiCH. TIMES DISPATCH, Jan. 21, 2004 , at D-8.

See Combs, supra note 9.

54 See Alan D. Woolf, Herbal Remedies and Children: Do They Work? Are They Harmful?, 112 PEDIATRICS 240, 240-46 (2003); see also H. C. Bucher, Effects of dietary calcium supplementation on blood pressure: $A$ meta-analysis of randomized controlled trials, 275 JAMA 1016,1022 (1996) (concluding that contrary to popular belief, calcium supplementation appears to promote no appreciable reduction in blood pressure); Michael L. Macknin et. al, Zinc Gluconate Lozenges for Treating the Common Cold in Children: A Randomized Controlled Trial, 279 JAMA 1962,1967 (1998) (finding that zinc offers no clinical value in treating the common cold).

${ }_{55}$ See Jon D. Hanson \& Douglas A. Kysar, Taking Behavioralism Seriously: Some Evidence of Market Manipulation, 112 HARV. L. REV. 1420, 1511 (1999).

56 See Jon D. Hanson \& Douglas A. Kysar, Taking Behavioralism Seriously: The Problem of Market Manipulation, 74 N.Y.U.L. Rev. 632, 657 (1999).

57 See Paul Slovic, Do Adolescent Smokers Know the Risks?, 47 DUKE L.J. 1133, 1137 (1998) (citing Neil D. Weinstein, Unrealistic Optimism About Susceptibility to Health Problems: Conclusions from a Community-Wide Sample, $10 \mathrm{~J}$. BEHAV. MED. 481, 488 (1987)).

${ }_{58}$ See Hanson \& Kysar, supra note 55, at 1512; see also Suzanne C. Segerstrom et al., Optimistic Bias Among Cigarette Smokers, 23 J. APPLIED SOC. PSYCHOL. 1606, 1614-17 (1993); Victor J. Strecher et al., Do Cigarette Smokers Have Unrealistic Perceptions of Their Heart Attack, Cancer, and Stroke Risks?, 18 J. BEHAV. MED. 45, 49 (1995).

See Jonathan D. Reppucci et al., Unrealistic Optimism Among Adolescent Smokers and Nonsmokers, 11 J. PRIMARY PREVEntIon 227, 235 (1991). But see W. Kip Viscusi, Constructive Cigarette Regulation, 47 DUKE L.J. 1095, 1113-14 (1998) (presenting evidence that optimism bias is unsupported in the context of cigarette smoking).

${ }^{60}$ See Hanson \& Kysar, supra note 55 , at 1514. 
tend to surmise unrealistically favorable expectations. ${ }^{61}$ This is especially true when short-term product use seldom results in injury, at least to consumers' physical appearance. $^{62}$

Moreover, in the midst of the ephedra fallout, some dietary supplement manufacturers have adroitly utilized the "irrelevant third option effect," whereby they market their products as "ephedra free" and thus of apparent less-risk. ${ }^{63}$ When any seller introduces irrelevant options, a consumer typically becomes biased in favor of options that he originally disfavored. ${ }^{64}$ Indeed, by framing the choice between something dangerous, something much less risky, and no action at all, supplement manufacturers may encourage new or continued use of supplements, much like the option of "unfiltered" or "light" cigarettes encourages would-be quitters to continue smoking. ${ }^{65}$

Individuals who lack significant resources are particularly vulnerable to choice distortions among dietary supplements. Indeed, those without access to health care often become heavy dietary supplement users. According to a December 2004 study released by the non-profit, non-partisan Center for Studying Health System Change, consumers who select supplements because they regard conventional treatments as expensive are almost twice as likely to earn incomes below the poverty line, significantly more likely to report poorer health status, and four times more likely to be uninsured. ${ }^{66}$ Equally troubling, the most popular supplements among low-income persons are those known to cause serious side effects, such as St. John's Wort and Kava. ${ }^{67}$ These consumption patterns are especially apparent among elderly persons who cannot afford prescription drugs, as they have increasingly turned to less expensive, but potentially dangerous, dietary supplements. ${ }^{68}$ For instance, many seniors purchase anti-oxidants, such as vitamin $\mathrm{E}$ and beta-carotene, largely based on the word-of-mouth belief that they prevent cancer. ${ }^{69}$ Available data, however, indicates no such discernable benefit; in stark contrast, those particular anti-oxidants have been associated with increased risk of lung cancer among smokers. ${ }^{70}$

\section{$61 \quad$ See id. \\ $62 \quad I d$. at 1515}

63 On May 18, 2005, a Google search of "ephedra free" yielded 421,000 results, and most of those results directed to websites that promoted the sale of "ephedra free" diet pills.

${ }_{64}$ See Hanson \& Kysar, supra note 55, at 1440 (noting this effect with the sale of used cars).

65 A similar concept would be how the presence of a delicious and fattening dessert option may encourage "would-be abstainers to order ice cream with fruit." Id. at 1515; see also Richard Saltus, Tobacco Critics Say "Lite" Label Misleads, BOSTON GLOBE, Jan. 31, 1997, at B2 (noting research that longtime smokers lose motivation to quit when they switch to lighter brands).

${ }_{66}$ See Ha T. TU \& J. LeE Hargraves, Ctr. For Studying Health Sys. Change, Data Bulletin No. 28: High COST OF Medical CARE Prompts Consumers to SeEk Alternatives (2004), available at http:/www.hschange.org/CONTENT/722/.

$67 \quad I d$.

68 See Johanna T. Dwyer et al., Assessing Nutritional Status in Elderly Patients, 47 AM. FAM. PhysiCIAN 63 (1993); see also Earl Lane, As More Seniors Turn to Supplements, More Data Needed, MilwaUkeE J. SeNTINEL, Feb. 3, 2004, at $01 \mathrm{G}$ (noting increasing trend of seniors to rely on dietary supplements for medicinal needs).

69 See Rebecca H. Madley, Reviving the Antioxidant Market, Nutraceuticals World, at http://www.nutraceuticalsworld.com/mar01 l.htm (last visited May 10, 2005).

${ }_{70}$ See Lane, supra note 68 (citing comments by Susan Mayne, a Yale University epidemiologist). On the other hand, preliminary, if inconclusive data suggests that Vitamin $\mathrm{E}$ can improve the immune response to respiratory tract infections among the elderly. See Simin Nikbin Meydani et al., Vitamin E and Respiratory Tract Infections in Elderly Nursing Home Residents, 292 JAMA 828,836 (2004). Similarly promising, if premature, findings have identified a positive correlation between Vitamin D consumption and reduced frequency of falling. See Heike A. BischoffFerrari et al., Effect of Vitamin D on Falls, 291 JAMA 1999, 2006 (2004). 
Adolescents are likewise malleable consumers of dietary supplements. This malleability partly relates to general characteristics of persons in that age group, as they have a greater tendency than adults to take dangerous risks, weigh short-term consequences more heavily than long-term consequences, and act impulsively. ${ }^{71}$ Such phenomena are especially evident among older adolescents, who tend to engage in risky and experimental behavior "as part of the process of separating from family and becoming autonomous." ${ }^{, 72}$ Moreover, adolescents often struggle with discriminating fact from fiction ${ }^{73}$ and are more likely than adults to uncritically ascribe to advice or suggestion. ${ }^{74}$ Dietary supplement companies are also presumably aware that young persons represent the most lucrative purchasing cohort of any age group ${ }^{75}$ and that their buying power has accelerated faster than that of any other age group in recent years. ${ }^{76}$

Data concerning dietary supplements use by student athletes uniquely illuminates the adolescent tendency to discount risk. For instance, most college athletes who use ephedra products became habitual users while playing sports in high school. ${ }^{77}$ It is thought that ephedra and similar stimulants offer the "extra edge" to perform, improve skill level, or help one become more athletic; ${ }^{78}$ correspondingly, many younger users are motivated by peer pressure ${ }^{79}$ or quixotic sports aspirations. ${ }^{80}$ Direct observations of supplement usage by role models only reinforce the availability and desirability of these stimulants. Children and adolescents may readily watch coaches, trainers, and teammates, as well as professional sports stars, use and promote dietary supplements. ${ }^{81}$ By forecasting unrealistic benefits and

1 See Thomas Grisso, The Competence of Adolescents as Trial Defendants, 3 PSYCH. PUB. POL. \& L. 3, 14; see also Barbara A. Atwood, The Child's Voice in Custody Litigation: An Empirical Survey and Suggestions for Reform, 45 ARIZ. L. REv. 629, 657 (2003); David E. Arredondo, Child Development, Children's Mental Health and the Juvenile Justice System: Principles for Effective Decision-Making, 14 STAN. L. \& POL'Y REV, 13, 15 (2003) (describing impulsive behavior of adolescents).

12 See Barry C. Feld, Competence, Culpability, and Punishment: Implications of Atkins for Executing and Sentencing Adolescents, 32 HOFSTRA L. REV. 463, 511 (2003); see also ERIK H. ERIKSON, IDENTITY YOUTH AND CRISIS 156 (1968) (describing the appeal of risk to adolescents, since it helps them find a role in society). Indeed, these phenomena help explain why "tobacco, alcohol, and illicit drug use begin most often between the ages of sixteen and eighteen." Elizabeth Cauffman \& Laurence Steinberg, The Cognitive and Affective Influences on Adolescent Decision-Making, 68 TEMP. L. REV. 1763, 1767 (1995).

See Angela J. Campbell, Ads2Kids.com: Should Government Regulate Advertising to Children on the World Wide Web?, 33 GoNZ. L. REV. 311, 320 (1997-1998).

${ }_{74} \quad$ See Atwood, supra note 71 , at 657.

75 See James U. MCNEAL, KIDS AS CUSTOMERS: A HaNdBook of MARKETING to CHILdREN $1-20$ (1992).

${ }_{76}$ See Karen E. Rondon, Innovations and Trends in the Electronic Toy Market, at 10 (SRI Consulting, Bus. Intelligence Program, No. D96-2028, 1996), available at http://www.sric-bi.com/; see also David Barboza, If You Pitch It, They Will Eat It, N.Y. TIMES, Aug. 3, 2003, § 3, at 1 (reporting that between their own spending and their influence on parental spending, children four- to twelve-years-old are responsible for approximately $\$ 600$ billion a year in expenditures).

77 See Money, supra note 10 (citing a study conducted by the NCAA).

78 See Steroids: Play Safe, Play Fair, American Academy of Pediatrics, at http://www.aap.org/family/steroids.htm (last visited May 10, 2005).

79 See Cara B. Ebbeling et al., Childhood Obesity: Public-Health Crisis, Common Sense Cure, 360 LANCET 473, 476 (2002).

${ }_{80}$ See generally Kelly Ann Kaczka, From Herbal Prozac to Mark McGuire's Tonic: How the Dietary Supplement Health and Education Act Changed the Regulatory Landscape for Health Products, 16 J. CONTEMP. HEALTH L. \& POL'Y 463 (2000).

81 See Money, supra note 10. 
depreciating risks, these impressions and exigencies merely exacerbate mythbelieving and optimism bias among a particularly vulnerable group.

Of similar concern, adolescents and young adults appear increasingly interested in creatine monohydrate supplements. These supplements elevate the body's supply of a compound found in the liver, pancreas, and kidneys, which ultimately becomes phosphocreatine, a source of energy for weight-lifting. ${ }^{82}$ According to the American Academy of Pediatrics, nearly 30 percent of college athletes use creatine, as do nearly 20 percent of high school juniors and seniors. ${ }^{83}$ More recently, non-athlete students have become frequent creatine customers, apparently motivated by a desire to look stronger and more attractive. ${ }^{84}$ However, neither the safety nor efficacy of creatine has been clinically determined, though commonly observed side effects include cramping and gastrointestinal upset; less often, kidney dysfunction has been reported. $^{85}$

Perhaps more disturbing, use of creatine and similar products may encourage the subsequent use of toxic and illegal substances, such as anabolic steroids. ${ }^{86}$ Indeed, the availability of such substances may endorse a socially-permissive attitude towards external enhancements, which might encourage a more lenient attitude toward steroid use. ${ }^{87}$ Separately, consider the salience of the irrelevant third option effect in the creatine consumer model: by framing the choice between a steroid, creatine, and no enhancement, manufacturers of creatine products likely encourage would-be non-purchasers of steroids to purchase creatine. ${ }^{88}$

Of course, distorted perceptions are not apparent solely among those of economic disadvantage or those in their childhood and adolescent years. Rather, consumers tend to assume a product's safety merely by virtue of the product's placement on a store shelf, particularly at established retail chains. Other consumers presumptively equate "natural" products with "harmless" products. ${ }^{89}$ Moreover, because dietary supplement manufacturers may readily advance disingenuous

82 See Jordan D. Metzl et al., Creatine Use Among Young Athletes, 108 PEDIATRICs 421, 421$22(\underset{83}{2001})$.

83 Id.

84 See Sameh Fahmy, Muscle Madness, ThE TENNESSEAN, May 11, 2004, at 1D (citing study conducted by Dr. Nick Evans of the UCLA Medical Center and Los Angeles Orthopedic Hospital).

${ }_{85}$ See Metzl et al., supra note 82; see also Kati Plax, Performance Enhances Pose Numerous Risks, ST. LOUIS POST-DiSPATCH, Oct. 4, 2004, at 8 (reporting side effects); Avi Salzman, Playing Fields and the Threat of Steroid Use, N.Y. TIMES, Dec. 19, 2004, $\S 14 \mathrm{CN}$, at 1 (providing additional background information on appeal of creatine to children and adolescents).

${ }_{86}$ See Jeremy Fowler, Clouds of Suspicion, AlBUQUERQUE TRIB., Nov. 27, 2004, at B1 (citing remarks by Professor Robert Robergs of the University of New Mexico, an expert on exercise physiology).

${ }_{87}$ See Metzl et al., supra note 82; see also Avi Salzman, Playing Fields and the Threat of Steroid Use, N.Y. TIMES, Dec. 19, 2004, at 1 (providing additional background information on appeal of creatine to children and adolescents). Not all studies identify health impairment with use of creatine. See e.g., J.R. Poortmans \& M. Franceux, Renal Dysfunction Accompanying Oral Creatine Supplements, 352 LANCET 234 (1998) (concluding that "medium-term oral creatine supplements do not affect kidney function in healthy individuals").

${ }_{88}$ See supra note 65 and accompanying text

89 See Brian F. McBride, Electrocardiographic and Hemodynamic Effects of a Multicomponent Dietary Supplement Containing Ephedra and Caffeine: A Randomized Controlled Trial, 291 JAMA 216, 221 (2004) (concluding that "consumers are drawn to herbal preparations because of their nonprescription status, direct-to-consumer advertising, and the perception that natural products are innately safe. Unfortunately, the perception of safety may be the result of a lack of data"); see also Susan Okie, Dietary Supplements Gaining Public Approval, If Not Government's, WASH. POST, Nov. 25, 1997, at Al (citing research conducted by Esther Sternberg, a rheumatologist with the National Institute of Mental Health, suggesting that consumers overestimate the degree of proven safety associated with dietary supplements). 
claims, they are able to utilize context-distortions to more generally mislead consumers. For instance, supplements which claim to "boost metabolism" and thereby facilitate bodybuilding often neglect to mention that only professional bodybuilders enjoy meaningful benefit. ${ }^{90}$

Similarly, consider the very real effect of celebrity product endorsements on consumer evaluation of dietary supplements. Although celebrities usually lack the requisite qualifications to knowledgeably dispense health-related advice, they are nevertheless employed with great alacrity by dietary supplement manufacturers. For instance, Phillip C. McGraw, Ph.D. (a.k.a. "Dr. Phil"), a trained psychologist but not a medical doctor, endorses energy bars and multivitamin supplements. ${ }^{91}$ Less credibly, self-help guru Anthony Robbins likewise endorses a brand of nutritional supplements. ${ }^{92}$ Similarly, actor James Brolin, who once starred as a physician in the television series "Marcus Welby, M.D.," now stars in promotions for a dietary supplement claiming to mitigate arthritis. ${ }^{93}$ Even unintentional endorsements have proven salient: sales of Zantrex-3-a diet pill containing high doses of caffeine, green tea, and three South American herbs-soared after pop star Brittany Spears spilled a bottle of the product with photographers nearby. ${ }^{94}$ Significantly, because consumers tend to regard the dietary supplement market as confusing and daunting, market experts find consumers are more likely to trust celebrity opinions of dietary supplements than of more familiar products. ${ }^{95}$

\section{Subjective Consumer Value AtTributable to Dietary Supplements}

The preceding sections paint an admittedly dim view of dietary supplements and their interaction with consumer choice. However, many dietary supplements have proven effective, and, even without clinical validation, have achieved support within the American medical community. ${ }^{96}$ This section will describe some of the more favorable aspects of dietary supplements, and why efforts to curtail their sale must be carefully tailored.

Proof of safety and effectiveness, at least in a clinical sense, is often hard to establish for dietary supplements. Without requisite assurances of product safety or stringent labeling guidelines, dietary supplement manufacturers lack the incentive to conduct exhaustive testing. This is particularly true given fierce industry

90 See 'Revving Up' on Hooey, WASH. Post, Aug. 26, 2003, at F3 (quoting David Nieman, director of the Human Performance Laboratory at Appalachian State University).

91 See Deardorff, supra note 16.

92 See id.

${ }_{93}$ See Lifestyles of the Sick and Famous, ALAMEDA TIMES-STAR, Nov. 17, 2002, at Opinions/Editorials. Brolin played Dr. Steven Kiley in the short-lived television series Marcus Welby, M.D. See INTERNET MOVIE DATABASE, Profile: JAMES BRolin, available at http://www.imdb.com/name/nm0000981/ (last visited Jan. 1, 2005).

$94 \quad$ See Michael Specter, Miracle in a Bottle, ThE NEW YORKER, Feb. 2, 2004, at 64.

95 See Deardorff, supra note 16 . Also consider that consumers may be confused by advice from physicians concerning dietary supplements, as physicians tend to embrace widely varied views of supplement efficacy. See Kenneth M. Davis et al., Physician Marketing of Nutritional Supplements, 280 JAMA 967, 968 (1998). Accordingly, it would appear that "celebrity" endorsements might achieve greater salience among consumers.

${ }_{96} \quad$ See Amber K. Spencer, Comment, The FDA Knows Best . . Or Does It? First Amendment Protection of Health Claims on Dietary Supplements: Pearson v. Shalala, 15 BYU J. PUB. L. 87 (2000); see also Rachel Brand, Hauser Tumbles into Chapter II, ROCKY MOUNTAIN NEWS, Apr. 3, 2003, at IB (detailing how Hauser, a dietary supplement manufacturer, blamed "intense competition in the dietary supplement industry" for its recent decision to declare bankruptcy). 
competition and the resulting "rush" to deliver products onto the market. ${ }^{97}$ Although independent supplement watchdog groups, such as ConsumerLab.com, regularly test dietary supplements for ingredient integrity and claim accuracy, such testing typically occurs well after a product's introduction into the stream of commerce. ${ }^{98}$

Predictably, the lack of uniform supplement testing often draws stern rebuke from traditional medical providers, who employ clinical testing to distinguish not only helpful from harmful products, but also modern from primitive medicines. ${ }^{99}$ Clinical testing measures biological plausibility, consistency and reproducibility of research, dose-response effects, strength of causal association, and correct temporality between cause and effect. ${ }^{100}$ Accordingly, without clinical testing, there exists considerable opportunity for unrealistic and deleterious practices, as well as misinterpreted results. For instance, in some primitive tribal communities, medical healers still treat AIDS with herbs. ${ }^{101}$ Despite using different herbs and dissimilar methods of preparation, they nevertheless believe their methodologies are effective. ${ }^{102}$ Similarly, without rigorous testing, contaminants and adulterants within supplements may pose unexpected danger. To illustrate, a recent seizure of 260 imported Chinese supplements by the California Department of Public Health revealed that over half of the supplements contained high levels of lead and arsenic. $^{103}$

Despite the absence of methodologically-deduced "proof," certain dietary supplements have been heralded by consumers. The herb ginseng, for instance, has been used for centuries by Tibetan people to improve endurance and memory; its relatively recent introduction into the United States market has evinced similar claims. ${ }^{104}$ Likewise, many consumers of elderberry extract insist that it alleviates flu

97 See Amy Shipley, New Steroids Sold Over Counter, WASH. POST, Dec. 6, 2002, at A1 (describing incentive for copy-cat practices among dietary supplement manufacturers given fierce market competition); see also Brand, supra note 96, at 1B.

${ }_{98} \quad$ See Jane E. Allen, A First Step Toward Standardizing Supplements, L.A. TIMES, Mar. 17, 2003, at 3; see also infra Part V.B.

99 See Joseph A. Page, The Passage of Time: The Implications for Product Liability, 58 N.Y.U.L. REv. 853, 869 (1983); see also S. Weingarten, Practice Guidelines and Prediction Rules Should be Subject to Careful Clinical Testing, 277 JAMA 1977, 1978 (1997) (describing significance of clinical testing guidelines in the medical review process). Note that, in light of international competition among drug manufacturers, the FDA has become arguably less demanding of American manufacturers in regards to clinical testing and clinical trials. See Nigel S. B. Dawson, Pharmacopolitics: Drug Regulation in the United States and Germany, 292 JAMA 742, 743 (2004).

${ }_{100}$ See Marcia Angell \& Jerome P. Kassirer, Alternative Medicine: The Risks of Untested and Unregulated Remedies, 339 NEW ENG. J. MED. 839 (1998); see also Jerry Hurst et. al, Are Physicians' Office Laboratory Results of Comparable Quality to Those Produced in Other Laboratory Settings?, 279 JAMA 468, 471 (1998) (distinguishing between varying clinical tests, including waived tests, provider-performed microscopy, and moderate-complexity and high-complexity tests).

${ }_{101}$ See Gerard Bodekar, A Regional Task Force on Traditional Medicine and AIDS, 355 LANCET 1284 (2000); see also Sanghavi, supra note 18 (illustrating lack of effectiveness among herbal remedies for AIDS); Austin Kaluba, More Research Needed in Zambian Herbal Medicines, TIMES ZAMBIA, Jan. 24, 2005, at 1 (describing use of herbs by Zambian medical healers).

102 Id.

103 See H.J. Kaltsas, Patent Poisons, ALtern Med., Nov. 1999, at 24-28; see also Richard J. Ko, Causes, Epidemiology, and Clinical Evaluation of Suspected Herbal Poisoning, $6 \mathrm{~J}$. TOXICOLOGY 697 (1999) (explaining inconsistent quality controls of Chinese manufacturers, and how the central government has limited authority and resources to regulate the dietary supplement industry).

${ }_{104}$ See generally A Herb a Day Keeps Doctors Away, CHINA DAILY, Oct. 27, 2003, available at LEXIS News Database. Recent data, however, suggests that ginseng may impair the absorption of anticlotting drugs. See Mike Mitka, Study Reveals Ginseng Supplements May Hamper Effects of Anticlotting Drug, 292 JAMA 674 (2004). It may also interfere with certain perioperative care 
symptoms. ${ }^{105}$ Although these findings represent anecdotal and unscientific evidence, they intimate that widespread clinical benefits may be associated with certain supplements.

Consumer impressions are also significant because certain supplements may subsequently receive clinical validation. For instance, scientists find that green tea extract and Chinese Red Yeast Rice feature anticancer effects. ${ }^{106}$ Perhaps most dramatically, consider artemisinin, an ancient Chinese herbal compound based on qinghasuu (sweet wormwood). Decades ago, Chinese doctors found that artemisinin significantly reduced the death rate of malaria patients without imposing serious side-effects. ${ }^{107}$ For years, westernized medical communities dismissed artemisinin's alleged prowess as mere mysticism. ${ }^{108}$ However, as malaria evolved into resistant strains against the drug Chloroquine, world health agencies reluctantly turned to the herbal compound. ${ }^{109}$ Later clinical studies have not only confirmed artemisinin's effectiveness, but now generally regard it as superior to Chloroquine. ${ }^{110}$

Along these lines, anthropological research may illuminate effective treatments among traditional medicines where clinical testing does not. ${ }^{11}$ Put differently, the clinical value of historical, albeit circumstantial findings can reveal unique and valuable information. For instance, consider the long-standing Laotian tradition of incorporating herbs into meals. ${ }^{12}$ Intriguingly, anthropologists find uncanny and detailed knowledge among Laotians about the ways in which each herb benefits the body, even though many Laotians lack formal education and even though such conclusions were originally drawn centuries ago, long before westernized testing of herbal efficacy. ${ }^{113}$

procedures. See Michael K. Ang-Lee et al., Herbal Medicines and Perioperative Care, 286 JAMA 208, 216 (2001).

105 See Lisa Liddane, No Flu Shot?, KNIGHT RIDder/Tribune News SERviCe, Nov. 12, 2004, available at LEXIS News Database. Historically, elderberry has not always been associated with positive medicinal effect. For instance, in 1984, eight Californians who consumed elderberry juice suffered acute gastrointestinal and neurologic symptoms, resulting in one hospitalization. However, such problems typically do not emerge when preparers of the juice remove the bits of leaves and stems from the berries. See Elderberry Poisoning, 29 AM. FAM. PHYSICIAN 346 (1984).

106 See Diet, Physical Activity, and Dietary Supplements - the Scientific Basis For Improving Health, Saving Money, and Preserving Personal Choice: Hearing Before the House Comm. on Gov't Reform, 107th Cong. (July 25, 2002) (statement of Dr. David Heber, Director Division of Clinical Nutrition, University of California). Recent data also suggests that Vitamin A supplements can lessen the severity of hip fractures among older women. See Diane Feskanich, Vitamin A Intake and Hip Fractures Among Postmenopausal Women, 287 JAMA 47, 54 (2002).

107 See Donald G. McNeil, Jr., Herbal Drug Widely Embraced In Treating Resistant Malaria, N.Y. TIMES, May 10, 2004, at 1 (noting that, in one outbreak in Vietnam, artemisinin allegedly cut the death rate by 97 percent).

108 See id.

109 See id.

110 See N.J. White et al., Comparison of Artemether and Chloroquine for Severe Malaria in Gambian Children, 339 LANCET 317-21 (1992); see also Rediscovering Wormwood: Qinghaosu for Malaria, 339 LANCET 649-51 (1992) (highlighting unexpectedness effectiveness of artemisinin); McNeil, supra note 107 (detailing how artemisinin has contained small outbreaks in mosquito-infested areas and prevented them from becoming epidemics). In fact, the resounding success of artemisin has encouraged the development of pharmaceutical derivatives of it and pyronaridin. See Bernard Pécoul et. al, Access to Essential Drugs in Poor Countries: A Lost Battle?, 281 JAMA 361, 367 (1999).

III See Kathy J. Kemper et al., Holistic Pediatrics: A Research Agenda, 103 Pediatrics $902-$ 09 (1999).

112 See Kerry Hughes, Functional Foods: Back to the Future, PREPARED Foods, Mar. 1, 2001, at 35 .

113 See id. Despite these anthropological findings, many western scientists remain skeptical. According to one study, the mere presence of "shamans" in Laos and throughout Southeast Asia may partly explain such skepticism, in that western scientists tend to dimly regard those who practice 
Furthermore, even when supplements lack measurable efficacy, they may nevertheless help persons cope with illness, particularly when compared to more stigmatizing modes of modern medical delivery. ${ }^{114}$ For instance, the steroid dehydroepiandrosterone (a.k.a. "DHEA") has been identified as improving mental well-being and reducing stress. ${ }^{115}$ Many consumers prefer its over the counter availability to stigmatizing or even embarrassing requests for prescription mental health medicines. ${ }^{16}$ Such subjective value comports with the modern description of "holistic medicine": care of the whole patient (body, mind, relationships, emotions, and spirit) in the context of the patient's values, culture, and community. ${ }^{117}$ Accordingly, medical care based entirely on statistical, biological, or genetic factors is unlikely to fully engage patients who have limited medical experience or technical prowess and whose explanatory models often encompass cosmic, karmic, or spiritual considerations. ${ }^{118}$ By contrast, dietary supplement consumption, like interaction in support groups and therapy, may yield methodologically-elusive, yet consistently discernable, therapeutic benefit.

Subjective value associated with dietary supplements may be compared to that of placebos. Indeed, physicians regularly employ placebos because they may induce psychological or physiologic therapeutic effects that "effective" medicine cannot. ${ }^{119}$ Moreover, placebos have been found not only to improve a patient's emotional wellbeing, ${ }^{120}$ but also to catalyze physical healing. ${ }^{121}$

On the other hand, the concept of distrust appears salient for both supplements and placebos. Indeed, one might negatively regard a dietary supplement company which knowingly markets inefficacious products in the same way one might regard a physician who "lies" to her patients by using placebos. Alternatively, from a consumer autonomy perspective, neither a patient who unknowingly purchases a

medicine without formal education or training. See Laura Uba, Cultural Barriers to Health Care for Southeast Asian Refugees, 107 PUB. HEALTH REP. 544, 548 (1992).

${ }_{114}$ See Sanghavi, supra note 18. For instance, mental hospitalization is often regarded as highly stigmatizing, and certain supplements may diminish the need for such hospitalization. See Daniel Luchins, Refusing Care: Forced Treatment and the Rights of the Mentally Ill, 290 JAMA 674, 675 (2003). Physicians can also be stigmatized by contemporary modes and norms of medical delivery. See e.g., Tracy Hampton, Physicians Advised on How to Offer Pain Relief While Preventing Opioid Abuse, 292 JAMA 1164,1162 (2004) (finding that physicians who prescribe pain medications often feel stigmatized within the health care community).

115 See Marilynn Larkin, DHEA: Will Science Confirm the Headlines?, 352 LANCET 208 (1998); see also Arline Kaplan, DHEA Lessens Depressive Symptoms, NIMH Study Shows, GERIATRIC TIMES, Nov. 1, 2004, at 4 (describing soon-to-be released study finding that that DHEA may prove more efficacious in treating mild-to-moderate midlife crisis than traditional antidepressant treatments).

116 Id. See also Luchins, supra note 114 , at 675 (describing stigma of pursuing mental health medicines).

${ }_{117}$ See Kemper et al., supra note 111; see also G. Yahn, The Impact of Holistic Medicine, Medical Groups, and Health Concepts, 242 JAMA 2202, 2205 (1979) (offering historical survey of holistic medicine and its systemic interaction with modern clinical expectations).

${ }_{118}$ See Delbanco T. Leeches, Spiders and Astrology: Predilections and Predictions, 280 JAMA $1560-62$ (1998).

${ }_{119}$ See Kathleen M. Boozang, The Therapeutic Placebo: The Case for Patient Deception, 54 FLA. L. REV. 687, 698-99 (2002); see also Barry Krakow et al., Placebo Effect in Posttraumatic Siress Disorders, 284 JAMA 563 (2000) (identifying short-term value of placebos in treating posttraumatic stress disorders).

${ }_{120}$ See Howard Brody, Placebos and the Philosophy of Medicine 16 (1980). Intriguingly, these and similar phenomena have been evident since the practice of ancient priests thousands of years ago. See Arthur K. Shapiro \& Elaine Shapiro, The Powerful Placebo: From ANCIENT PRIEST TO MODERN PHYSICIAN (1997).

I21 Id. at 9 . 
placebo nor a consumer who unknowingly purchases an ineffectual supplement intends to purchase those items. These varying viewpoints underscore concern that certain supplement companies deceive consumers, thus diminishing their products' perceived therapeutic effect-much like concern that by undermining patient confidence in the physician, placebos may diminish their perceived effect. ${ }^{122}$

\section{DIETARY SUPPLEMENT LAWMAKING \& CONSUMER NORMS}

Identifying normative consumer interaction with dietary supplements invariably links to legal treatment of those supplements. Indeed, in a free market, lawmakers ultimately choose the extent to which governmental regulation should steer products and industries, and the extent to which consumers may choose risk. Common considerations include requisite thresholds of product safety and effectiveness, as well as desirable levels of governmental supervision. ${ }^{123}$ Less nobly, other considerations might include lobbying interests and political fundraising implications. ${ }^{124}$

In the last century, legislative treatment of dietary supplements has evoked myriad considerations, often mixing economic constraints, social theory, and political pretext. This Part will explore the evolution of American dietary supplement law and how contrasting interests among the FDA, Congress, the dietary supplement industry, and supplement users have influenced promulgation of laws affecting dietary supplement consumption. This exploration may also illuminate potentially beneficial changes in both regulatory authority and industry behavior, particularly regarding consumer recognition of risk and benefit.

\section{A. The EARly Years: Minimal Dietary Supplement Regulation}

Until the mid-19th century, dietary supplements, like most food and drugs, were largely unregulated. ${ }^{125}$ To the extent consumers received legal protection, it was primarily based on state common law, with typical claims involving heavilymarketed though highly-ineffective products, such as those basing their efficacy on "secret formulas." 126 Despite vast fraudulence, 19th century state tort laws scantly recognized product liability, thus making cognizable claims difficult to establish. ${ }^{127}$ Further burdening plaintiffs, courts would often legitimize "secret formulas" as genuine ingredients. ${ }^{128}$ This was particularly evident among herbal products. ${ }^{129}$

122 See Boozang, supra note 119 , at 743.

123 See 109 CONG. REC. E316 (daily ed. Mar. 1, 2005) (statement of Rep. Moran); H.R. Res. 135, 109th Cong. (2005). Emanuel).

124 See generally 109 CONG. REC. H2534 (daily ed. Apr. 26, 2005) (statement of Rep.

${ }_{125}$ For an extensive historical review of food and drug law, see generally Peter B. Hutt \& Peter B. Hutt II, A History of Government Regulation of Adulteration and Misbranding of Food, 39 FoOD Drug Cosm. L.J. 2 (1984). See also Peter Barton Hutt \& Richard A. Merrill, Food and Drug LAW: CASES \& MATERIALS 6-10 (1991).

126 See Howard A. Denemark, Improving Litigation Against Drug Manufacturers for Failure to Warn Against Possible Side Effects: Keeping Dubious Lawsuits from Driving Good Drugs Off the Market, 40 CASE W. RES. L. REV. 413, 415-16 (1990); see generally STEWART H. HOLBROOK, THE GOLDEN AGE OF QUACKERY 14-28 (1959) (providing extensive information on some of the most outrageous products, many of which were heavily marketed).

127 Id. at 416 .

128 Id. (discussing how "quacks" were undeterred by legal institutions and the law). 
Along these lines, distinction between "drug" and "dietary supplement" products appeared fleeting. For instance, in Bailey v. Moog, ${ }^{130}$ a New York court heard the claim of a physician whose prescriptive practice in 1847 comprised solely of roots, barks and herbs. ${ }^{131}$

In 1850, however, the Massachusetts Sanitary Commission released an influential report connecting toxic sewage and contaminated food and drug products to declining mortality rates. ${ }^{132}$ Following the report, states began to enact more stringent health laws, including those which prohibited adulterated food. ${ }^{133}$ However, many of these laws reflected disparate policies and lacked uniform construction, thus resulting in substantial consumer confusion. ${ }^{134}$

During this time period, federal powers to regulate food and drugs proved especially restrained. Despite the lobbying efforts of reform movements-including those initiated by merchants themselves ${ }^{135}$ - as well as the late-19th century crusade of Dr. Harvey Washington Wiley, Chief Chemist for the U.S Department of Agriculture and legendary consumer advocate, ${ }^{136}$ the Supreme Court's interpretation of the scope of the commerce clause constrained efforts to enact stringent food and drug law. ${ }^{137}$ The essence of such interpretation significantly limited the scope of federal commerce law to transactions which physically crossed state borders; at the time, many food and drug transactions comprised intrastate activity. ${ }^{138}$ On the other hand, the federal government could attempt to regulate food and drugs through the Postmaster General's authority to withhold delivery of fraudulent mail, but this authority often proved inadequate. ${ }^{139}$

In 1906, however, Congress reconsidered federal food and drug legislation, particularly in light of increasing attention on "quackery." 40 Publication of Upton

129 See, e.g., In re Eisner, 1893 U.S. App. LEXIS 2502 (C.C.S.D.N.Y. 1893) (noting that "[t]he Johann Hoff Malt Extract is a compound of many ingredients, made by a secret formula, consisting of herbs, roots, leaves, dextrine, water, hop extract and malt extract").

1301847 N.Y. LEXIS 54 (N.Y. 1847).

131 Id. at *3; see also In re Hunter, 60 N.C. 447 (1864) (court distinguishing "physical herb" from "medical herb").

132 See Stephen B. Thacker, Historical Development in Principles and Practice of Public Health Surveillance 3, 4 (Steven M. Teutsch \& R. Elliot Churchill eds., 1994).

133 For instance, Dr. E.R. Squib, a merchant, spoke publicly about rampant fraud in the food and drug industry, and the need to separate legitimate merchants from illegitimate ones. Other reform parties included the American Medical Association, the American Public Health Association, labor unions, and consumer groups. See Richard A. Merrill \& Jeffrey K. Francer, Organizing Federal Food Safety Regulation, 31 SETON HALL L. REV. 61, 79 (2000).

${ }_{134}$ See Peter Barton Hutt, Lecture at Harvard Law School, Jan. 4, 2005 (comments on file with author).

135 See HUTT \& MERRILL, supra note 125 , at 7-9.

136 Dr. Washington waged an uphill battle against fraudulent drugs and adulterated foods. To prove his beliefs, he even assembled a "poison squad," a group of assistants who would test contaminated food and drug products and then publicize the conclusions. See HARRY E. NEAL, THE Protector's: The STORy OF THE FoOd AND DRUg Administration 12 (1970).

137 See Richard A. Epstein, Our New Federalism? National Authority and Local Autonomy in the War on Terror, 69 BROOKLYN L. REV. 1421 (2004).

138 See id.

139 See, e.g., American School of Magnetic Healing v. McAnnulty, 187 U.S. 94, 109-10 (1902) (finding that even when determining the fraudulence of a product, the Postmaster General lacked the ability to make conclusions of law); Peter Barton Hutt, A History of Government Regulation of Adulteration and Misbranding of Medical Devices, 44 FOOD DRUG COSM. L.J. 99, 101-02 (1989) (noting how the FDA regularly collaborated with the Post Office in policing fraudulent food and drug practices).

140 See Scott Bass \& Alan Raul, The Single Food Safety Agency: A Modest Dialectic Dialogue, 59 FOOD DRUG L.J. 453, 455 (2004). 
Sinclair's The Jungle, ${ }^{141}$ which dramatically illustrated the abundance of contaminants in the food supply, only propelled legislative interest. ${ }^{142}$ With sufficient momentum, Congress passed and President Theodore Roosevelt signed the Pure Food and Drugs Act of 1906 ("1906 Act"). ${ }^{143}$

Upon initial observation, the 1906 Act reflected "progressive legislation," since, for the first time, the shipment of adulterated food and drugs was prohibited in interstate commerce. ${ }^{144}$ The 1906 Act also empowered the FDA to pursue seizures and other enforcement mechanisms against non-compliant food and drug companies. $^{145}$

Nevertheless, the 1906 Act placated private industry by requiring the federal government to discover dangerous food ingredients after a product entered the market. ${ }^{146}$ In contrast to pre-market approval or mandatory disclosure from private industry, this approach offered limited certainty for consumers, particularly given minimal enforcement resources. ${ }^{147}$ Similarly restraining, though the 1906 Act prohibited "dangerous" food ingredients, it largely preserved companies' capacity to promote misleading claims. ${ }^{148}$ Though Congress would pass the Shirley Amendment $^{149}$ to the 1906 Act in 1912, it too would prove restrictive, since sustaining a charge that labeling was "false and fraudulent" obligated the government to prove not only that the claims were untrue, but that the seller knew they were untrue. ${ }^{150}$ Perhaps most significantly, the 1906 Act declined to impose nutritional or ingredient labeling requirements, aside from the disclosure of narcotic drugs and net weight. ${ }^{151}$

By using the state police power, however, several states imposed greater disclosure requirements on food labels, a trend supported by some courts. For instance, in 1906, Indiana passed a law requiring the disclosure of ingredients in animal food. In Savage v. Jones, ${ }^{152}$ the U.S. Supreme Court held that the act did not violate the Commerce Clause, merely reflected a valid exercise of the state police power, and was not preempted by the 1906 Act. ${ }^{153}$ This holding proved notable, particularly in light of the Court's 1905 holding in Lochner v. New York, ${ }^{154}$ which

141 UPTON SINCLAIR, THE JUNGLE (1906).

142 See Merrill \& Francer, supra note 133, at 79.

143 Pub. L. No. 59-384, § 2, 34 Stat. 768 (1906).

144 See Hipolite Egg Co. v. United States, 220 U.S. 45, 54 (1911) (holding that the purpose of the 1906 Act was to keep misbranded and adulterated products "out of the channels of interstate commerce, or, if they enter such commerce, to condemn them while being transported or when they have reached their destinations, provided they remain unloaded, unsold or in original unbroken packages").

145 See HUTT \& MERRILL, supra note 125 , at 8-9.

146 Pure Food and Drugs Act of $1906 \S 2$.

147 Id: see generally MARION NESTLE, FOOD POLITICS: HOW THE FOOD INDUSTRY INFLUENCES NUTRITION AND HEALTH (2002) (noting historical lack of resources for FDA). For an expanded discussion of the Pure Food and Drugs Act, see Lars Noah \& Richard A. Merrill, Starting from Scratch?: Reinventing the Food Additive Approval Process, 78 B.U. L. REV. 329, 331 (1998).

${ }_{148}$ See United States v. Johnson, 221 U.S. 488, 497-98 (1911) (Justice Holmes holding that a false claim to cure cancer did not satisfy the requirement that the claim be dangerous). But see Laufer T. Hayes \& Frank J. Ruff, The Administration of the Federal Food and Drugs Act, 1 LAW \& CONTEMP. PROBS. 16 (1933) (noting that the 1906 Act prohibited false claims).

149 Pub. L. No. 62-301, 37 Stat. 416 (1912)

150 See Merrill, supra note 31 , at 1760-61.

151 See generally Hayes \& Ruff, supra note 148.

152225 U.S. 501 (1912).

153 Id. at 531 (holding that "Congress has thus limited the scope of its prohibitions. It has not included that at which the Indiana statute aims").

154198 U.S. 45 (1905). 
established a thirty-year judicial skepticism towards most public interest legislation. $^{155}$

\section{B. The FDCA \& Food Additives Amendment: Moderate Dietary SUPPLEMENT REGULATION}

Despite the presence of more stringent state labeling laws, the need for enhanced federal food and drug legislation became apparent in 1938, when seventythree people died from ingesting Elixir Sulfanilamide, which had not been tested prior to its introduction on the market. ${ }^{156}$ Later that year, Congress replaced the 1906 Act with the FDCA, ${ }^{157}$ which enlarged FDA authority to regulate food and drugs. The FDCA also established jurisdictional boundaries between the FDA and the Federal Trade Commission, with the FDA and FTC receiving primary jurisdiction for labeling and advertising, respectively. ${ }^{158}$

Notably, for the first time, Congress described dietary supplements as a category of food for "special dietary purposes"159 and, under Section 403(j), authorized the FDA to promulgate regulations pertaining to those purposes. ${ }^{160}$ Specifically, Section 403(j) required that manufacturers label supplements with content information, including the amount of vitamins, minerals, and other properties. ${ }^{161}$ Foods offered for "special" dietary uses, therefore, warranted greater regulatory attention than regular foods.

The FDCA contained certain limitations, however. Specifically, it both preserved the absence of premarket approval and imposed minimal disclosure requirements. ${ }^{162}$ As a result, dietary supplements could continue to enter the market without significant safeguards. Moreover, in light of the FDCA's bounded counters, the FDA initially promulgated dietary supplement regulations of mixed effect. ${ }^{163}$ Consider the agency's first such set of regulations in 1941. ${ }^{164}$ At first glance, they appeared compelling, as they stipulated minimal daily requirements and labeling guidelines for vitamins and minerals. ${ }^{165}$ They also further refined the definition of "special dietary uses," including uses which "exist by reason of a physical, physiological, pathological or other condition." 166 On the other hand, because the FDCA only empowered regulation of supplement labeling, the FDA could not

\footnotetext{
155 See Nickolai G. Levin, Constitutional Statutory Synthesis, 54 ALA. L. REV. 1281, 1328-29 (2003).

See David F. Cavers, The Food, Drug, and Cosmetic Act of 1938: Its Legislative History and Its Substantive Provisions, 6 LAW \& CONTEMP. ProBs. 2, 20 (1939). Also significant was the 1917 Report of the USDA Bureau of Chemistry, which advocated greater FDA enforcement powers. See HUTT \& MERRILL, supra note 125 , at 10-11.

$\begin{aligned} 157 & \text { Pub. L. No. 75-717, } 52 \text { Stat. } 1040 \text { (1938) (cod } \\ (2000)) & \text { See HUTT \& MERRILL, supra note } 125 \text {, at } 187 .\end{aligned}$

159 Gardner v. Toilet Goods Ass'n, 387 U.S. 167, 180 (1967) (citing 21 U.S.C. $\$ 343(j)$ ).

16021 U.S.C. $\$ 403(j)(2000)$.

161 See id. (including under the definition of misbranded food any item which "purports to be or is represented for special dietary uses, unless its label bears such information concerning its vitamin, mineral, and other dietary properties as the Secretary determines to be, and by regulations prescribes as, necessary in order to fully inform purchasers as to its value for such uses").

${ }_{162}$ For a discussion, see Noah \& Merrill, supra note 147, at 331-34.

163 See Meghan Colloton, Dietary Supplements: A Challenging Facing the FDA in Mad Cow Disease Prevention, 51 AM. U. L. REV. 495, 512 (2003).

16421 C.F.R. $\$ 125(1941)$.

16521 C.F.R. $\$ 125$.

166 6 Fed. Reg. 5921 (1941).
} 
address the safety and efficacy of the supplements themselves. ${ }^{167}$ Rather, the FDA merely required a label disclaimer that the values of supplements "in human nutrition have not been established." 168 Perhaps not surprisingly, these regulations encountered minimal resistance from the courts, the dietary supplement industry, and consumers. ${ }^{169}$

Nevertheless, food safety improved significantly around this time, as food companies more regularly tested their ingredients. ${ }^{170}$ Such enhanced voluntary behavior partly reflected the burgeoning viability of private tort liability, ${ }^{171}$ as well as the mere threat of adverse publicity, which became more prevalent with the rise of radio and television media. ${ }^{172}$ Moreover, though the FDA's continued burden of discovering dangerous ingredients hampered regulatory enforcement, the agency appeared uniquely resilient in ensuring accurate supplement labeling. ${ }^{173}$ This resilience was best evidenced by the Nutrilite Consent Decree, ${ }^{174}$ which, through a series of litigations, resulted in new guidelines for dietary supplement companies that discouraged false claims. ${ }^{175}$ The FDA also benefited from a fairly liberal judicial interpretation of "labeling" under the FDCA. Specifically, in Kordel $v$. United States, ${ }^{176}$ the U.S. Supreme Court held that pamphlets and other advertisements mailed separately from products and their attached labels are included within the statutory definition of "labeling."

Subsequent legislative initiatives only buttressed the FDA. Namely, by passing the Food Additives Amendment to the FDCA ${ }^{178}$ in 1958, Congress established a premarket approval system for food ingredients. Legislative desire to do so derived from concern over the growing use of chemicals in foods. ${ }^{179}$ Through the Food

167 See Kaczka, supra note 80, at 468; see also Michael F. Markel, Foods for Special Dietary Uses-An Historical Outline of Regulatory Aspects, 22 FOOD DRUG COSM. L.J. 110, 114 (1967).

${ }_{168}$ See, e.g., 6 Fed. Reg. 5921, 5925 (Nov. 22, 1941); 6 Fed. Reg. 3304, 3310 (July 8, 1941); 5 Fed. Reg. 3565 (Sept. 5, 1940); see also Margaret Gilhooley, Herbal Remedies and Dietary Supplements: The Boundaries of Drug Claims and Freedom of Choice, 49 FLA. L. REV. 665,672 (1997) (describing the limitations of such regulatory language).

169 See 1. SCOTT BASS \& ANTHONY L. YOUNG, DieTARY SUPPLEMENT HEALTH AND Education ACT: A Legislative History AND ANALYSIS 9 (1996).

170 See Noah \& Merrill, supra note 147, at 336 (citing Food Additives: Hearings Before a Subcomm. of the House Comm. on Interstate and Foreign Commerce, 85th Cong. $421-22$ (1957) (statement of Elliot L. Richardson, Asst. Secretary, Health, Education \& Welfare (HEW) ("The commendable actions of the great majority [of companies], however, cannot provide protection against the minority. We have had some narrow escapes in the food field."))).

171 See Robert C. Brown, The Liability of Retail Dealers for Defective Food Products, 23 MINN. L. REV. 585, 596-610 (1939).

172 See Noah \& Merrill, supra note 147 , at 336.

173 See Peter Barton Hutt, Government Regulation of Health Claims in Food Labeling and Advertising, 41 FOOD DRUG COSM. L.J. 3 (1986).

${ }_{174}$ United States v. Mytinger and Casselberry, Inc. FDA Not. of Jud. No. 3383 (S.D. Cal. 1951), reprinted in FEDERAL FOOD DRUG AND COSMETIC ACT 1951-1952, at 204 (FDLI 1953).

See Hutt, supra note 173, at 52; see also Lester L. Lev, The Nutrilite Consent Decree, 7 Food DRUG COSM. L.J. 56, 56 (1952); Kaczka, supra note 80, at 471 (contending that the FDA successfully pursued implementing the Nutrilite Consent Decree); Mark A. Kassel, From A History of Near Misses: The Future of Dietary Supplement Regulation, 49 FOOD \& DRUG L.J. 237 (1994) (finding that while the FDA generally failed to use litigation to ensure safety of food products, the agency perceived greater success with dietary supplements, particularly through the NCD).

$176 \quad 335$ U.S. 345 (1948)

$177 \quad I d$. at $349-50$.

178 Food Additives Amendment of 1958, Pub. L. No. 85-929, 72 Stat. 1784 (codified as amended in scattered sections of 21 U.S.C. $(2000)$ ).

179 See Noah \& Merrill, supra note 147 , at 336-40. 
Additives Amendment, Congress shifted the burden of proving food safety from the FDA to individual manufacturers, as it mandated that food additives-but not food ingredients - could be used only with prior FDA approval. ${ }^{180}$ Equally important, the Food Additives Amendment included dietary ingredients in the definition of a food additive, thus imposing the more stringent treatment if those ingredients were not GRAS. $^{181}$

\section{1960S-1980s: Product Proliferation \& INTEREst Group Manipulation}

Despite enhanced oversight powers, the FDA struggled to regulate dietary supplements, particularly as they proliferated in the early $1960 \mathrm{~s} .{ }^{182}$ Indeed, though the FDA brought hundreds of court actions against misleading supplement claims in the $1960 \mathrm{~s}$, case-by-base enforcement proved of limited effectiveness. ${ }^{183}$ This was especially true of herbs, which often blurred the line between medicine and food. ${ }^{184}$ Since neither the FDCA nor its implementing regulation specified the requisite dietary properties of herbs, the FDA possessed scant regulatory authority to combat such "quackery." 85 Illustrating the agency's frustration at that time, then FDA Commissioner George P. Larrick characterized dietary supplements as "the most widespread and expensive type of quackery in the United States."

In response to the proliferation of inefficacious dietary supplements, the FDA attempted to revise its regulations in 1962, proposing clear potency levels on vitamins and minerals, and requiring that supplements contain ingredients of established nutritional quality. ${ }^{187}$ These proposed regulations underscored the FDA's belief that dietary supplements should augment nutritional needs, ${ }^{188}$ such as presumed widespread nutritional deficiency among the population, rather than mythical wants. ${ }^{189}$ Of perhaps equal importance, the political climate for such industry-averse regulations may have appeared hospitable. Indeed, Congress had passed the Kefauver-Harris Amendment ${ }^{190}$ in 1962, thereby establishing FDA premarket approval of drug efficacy claims. ${ }^{191}$

$180 \quad I d$

181 See Stephen H. McNamara, Dietary Supplements of Botanicals and Other Substances: $A$ New Era of Regulation, 50 FOOD \& DRUG L.J. 341 (1995).

182 See generally HUTT \& MERRILL, supra note 125.

183 See id. at 207 n.2; see also Gilhooley, supra note 168, at 673 (describing the ineffectiveness of the case-by-case approach).

${ }^{184}$ See Kaczka, supra note 80 , at 471-72; see also William R. Pendergast, Dietary Supplements, in 1 FUNDAMENTALS OF LAW AND REGULATION 266 (FDLI 1997).

I85 See Kassel, supra note 175 , at 262.

186 Sean Harmon, Melatonin Mania: Can the FDA Regulate Hormonal Dietary Supplements to Protect Consumer Interests in Light of the Dietary Supplement Health and Education Act of 1994 ?, 22 Dayton L. REV. 77, n. 2 (1996) (citing Ralph L. Smith, The Vitamin Healers, THE REPORTER, Dec. 16,1965 , at 18-25).

187 See Dietary Foods, 31 Fed. Reg. 8521, 8522 (June 18, 1966).

$188 \quad 27$ Fed. Reg. 5815 (June 20, 1962).

189 See Gilhooley, supra note 168, at 673; see also William W. Goodrich, The Coming Struggle over Vitamin-Mineral Pills, 20 BUS. LAW. 145 (1964) (describing how dietary supplement manufacturers often asserted that daily food consumption failed to provide sufficient nutrients).

190 Pub. L. No. 87-781, 76 Stat. 780 (1962) (codified at 21 U.S.C. $\$ 355(2000)$ ) (the amendment is also commonly known as the "Drug Efficacy Amendment").

191 The requisite political support for the Kefauver-Harris Amendment was derived largely from the thalidomide tragedy. The pre-market approval process of claims required controlled studies, unless the product was generally recognized by experts as effective based on similar studies. See generally Gilhooley, supra note 168, at 672 . 
Despite agency momentum and conceivably opportune political timing, the FDA encountered significant resistance to its proposed reforms. Of greatest challenge, a significant percentage of supplement consumers believed in unsubstantiated product assertions, and many campaigned against potency limits and other restrictions on their preferred products. ${ }^{192}$ These quixotic beliefs partly related to unregulated supplement claims, which often revealed information in promotional or misleading schemes. ${ }^{193}$ To the dismay of many consumers, the proposed regulations would have severely curtailed the sale of multi-vitamin and mineral products, as many of those products exceeded potency levels or utilized unreliable ingredients. ${ }^{194}$ As a result, an emboldened dietary supplement industry lobbied Congress to dismiss the proposals and even to refrain from holding public hearings. ${ }^{195}$

Four years later, the FDA proposed a new line of dietary supplement regulations, which continued to advance potency limits, but also proposed that dietary supplement labels include the following stark warning: "there is no scientific basis for recommending routine use of dietary supplements."196 The proposal sparked a five-year battle between the FDA and the dietary supplement industry, much of which transpired during acrimonious public hearings. ${ }^{197}$

The White House Conference on Food, Nutrition, and Health in 1969 ("White House Conference") also proved salient in the controversy. That year, President Richard M. Nixon convened leaders in the food and drug industry to develop antihunger strategies for poorer American communities, but the conference ultimately produced a Conference Report condemning a restrictive approach to dietary supplements and their labels. ${ }^{198}$ The Report instead championed the ability of emerging food technology to help consumers satisfy their nutritional needs, as well as the potential for labeling to inform consumers rather than set rigid standards for product composition. ${ }^{199}$

In response to the White House Conference and public hearings, the FDA published final regulations in 1973 ("the 1973 regulations") that were set to take full effect in $1975 .^{200}$ These regulations resembled those proposed in 1966, but did not include the warning label. ${ }^{201}$ Significantly, by establishing potency limits, the regulations required that any vitamin or mineral with a dosage exceeding 150 percent of the recommended daily allowance be subjected to the more arduous drug approval process. ${ }^{202}$ Of equal significance, the regulations stipulated that excessive

192 Id. at 673.

193 See generally id.

194 See 27 Fed. Reg. 5815, 5815 (1962); Kaczka, supra note 80, at 472.

195 See Goodrich, supra note 189.

196 Dietary Foods, 31 Fed. Reg. 8521, 8525 (proposed June 18, 1966).

197 See Definition, Identity, and Label Statements; Proposed Findings of Fact, Conclusions, and Tentative Order Following a Public Hearing, 38 Fed. Reg. 2152, 2153 (proposed Jan. 19, 1973) (outlining hearings that led to 1973 proposed rule making). For an excellent review of the hearings, see Colloton, supra note 163, at 515-16.

${ }_{198}$ See Peter Barton Hutt, Regulating the Misbranding of Food, 43 FoOD TECH. 288 (1989); see also Hutt, supra note 167 (describing significance of contemporaneous staff changes at the FDA).

199 Id.

200 See Dietary Supplements of Vitamins and Minerals, 38 Fed. Reg. 20730, 20731 (Aug. 2, 1973) (codified at 21 C.F.R. $\$ \S 105.3,105.60,105.77,105.85$ (2005).

$201 \quad I d$.

202 See 38 Fed. Reg. 20716 (1973). 
doses of certain ingredients would statutorily convert affected supplements into drugs, unless the manufacturer demonstrated a nutritional need for the dose. ${ }^{203}$

Despite omitting the warning label requirement, the 1973 proposal attracted considerable criticism from the dietary supplement industry, particularly in regards to its potency limits and its statutory conversion of certain supplements into drugs. ${ }^{204}$ Similarly influential, the problem of "hunger in America" became paramount in media coverage and political rhetoric. ${ }^{205}$ Such criticism immediately spawned litigation. In National Nutritional Foods Association v. Food \& Drug Administration, ${ }^{206}$ the U.S. Court of Appeals for the Second Circuit fielded legal objections from fifteen parties-primarily vitamin and food supplement manufacturers-concerning whether the FDA possessed the authority under the FDCA to set qualitative and quantitative standards of identity for dietary supplements containing vitamins and minerals. ${ }^{207}$ The court offered a mixed result, largely sustaining the potency limits ${ }^{208}$ but finding unreasonable the rules governing supplements which exceeded the recommended daily allowances. ${ }^{209}$ Similarly mixed was the court's reasoning that a supplement could not be considered a drug unless its manufacturer so "intended," and that intent could not be determined solely by nutritional usefulness, as argued by the FDA, or by the manufacturers' claims, as argued by the manufacturers, but rather by a nebulous middle ground. ${ }^{210}$

Many industry and consumer groups were dissatisfied with National Nutritional Foods Association, as potency limits deterred research and development of highpotency supplements, with manufacturers sufficiently dissuaded by the costs and delays commonly associated with the drug review process. ${ }^{211}$ In response to intense industry lobbying efforts, Congress passed the Vitamin-Mineral Amendment of $1976^{212}$ (more commonly known as the "Proxmire Amendments"), which amended the FDCA by largely removing the teeth of FDA dietary supplement regulation. Specifically, the Proxmire Amendments eliminated maximum limits on the potency of supplements ${ }^{213}$ and on combinations of vitamins and minerals ${ }^{214}$ and prohibited the classification of any supplement as a drug based on presumptively excessive potency. ${ }^{215}$

203 See 38 Fed. Reg. 20708, 20730 (1973).

204 In fact, there were nearly 22,000 responses to the proposed regulations. See Colloton, supra note 163, at n.140 (citing 38 Fed. Reg. 20730). It is arguable that RDAs had originally been devised as a measurement standard for scientific and governmental research purposes, not as an enforceable standard for the general population. See MONICA MILLER, Foundation fOR THE ADVANCEMENT OF INNOVATIVE MEdicine, The History of Dietary Supplement Regulation, available at http://www.faim.org/supplements.htm (last accessed May 31, 2005).

205 See HUTT \& MERRILL, supra note 125, at 215.

206504 F.2d 761 (2d Cir. 1974).

207 Id. at 767.

208 Note that, even with potency limits, consumers could still digest the same level of supplements by consuming a greater number of reduced-sized tablets. See National Nutritional Foods, 504 F.2d at 792 (Judge Friendly suggesting that consumers could "take as many more tablets" as needed to procure the desired effect).

209 Id. at $783-84$.

210 Id. at 789 ; see Gilhooley, supra note 168 , at 674 (explaining how "intent" was proscribed).

211 See BASS \& YOUNG, supra note 169, at 12; see also Kassel, supra note 175, at 257 (detailing lobbying efforts).

212 Pub. L. No. 94-278, 90 Stat. 410 (1976) (codified as amended at 21 U.S.C. $\$ 350(2000)$ ).

213 See 21 U.S.C. $\$ 350($ a)(1)(A) (2000).

214 See 21 U.S.C. \$ $350(\mathrm{a})(1)(\mathrm{C})(2000)$.

$215 \quad$ See 21 U.S.C. $\$ 350(a)(1)(B)(2000)$. 
Taken together, National Nutritional Foods Association, the Proxmire Amendments, and the increasingly accordant relationship between Congress and the dietary supplement industry severely discouraged FDA efforts to regulate supplements. In fact, by the early 1980s, the agency scaled back its regulatory efforts $^{216}$ and, as a general matter, pursued enforcement action against dietary supplement companies only when supplements made either express drug claims or outrageous declarations. ${ }^{217}$ With such diminished deterrence, the number of supplements on the market exploded. ${ }^{218}$ The frequency with which these products made health related claims on packaging also increased. ${ }^{219}$

By the end of the 1980s, however, greater public attention to the dangers of unregulated dietary supplements arose, particularly since unfounded, confusing, and misleading disease claims were omnipresent on most dietary supplement labels. ${ }^{220}$ This was perhaps best evidenced by the amino acid dietary supplement L-trytophan, to which the federal Centers for Disease Control attributed thirty-eight deaths in $1989 .^{221}$ Less troubling only in comparison, many dietary supplements promoted audacious claims without even minimal scientific support. ${ }^{222}$

\section{Nutrition Labeling and EduCAtion ACt of 1990: LABEling Wars Begin}

Motivated partly by concern that consumers lacked sufficient nutritional information for dietary supplements, ${ }^{223}$ Congress passed the Nutrition Labeling and Education Act of 1990 ("NLEA") 224 to strengthen the FDA's legal authority to require nutritional labeling on food. ${ }^{225}$ Specifically, the NLEA added two subsections-(q) and (r) - to Section 403 of the FDCA, thereby creating two new food-labeling provisions. ${ }^{226}$ Section $403(\mathrm{q})$ specifies the general nutritional labeling standards and requirements, while section 403(r) prohibits food manufacturers from making unsubstantiated disease prevention or nutrient description claims. ${ }^{227}$ Though the NLEA authorized health claims for foods, it required that such claims receive premarket approval from the $\mathrm{FDA}^{228}$ and be based on well-designed studies and

216 See Gilhooley, supra note 168, at 676; see also General Accounting Office, Report to Senator Kennedy, at 4 (B252966, July 2, 1993), reprinted in BASS \& YOUNG, supra note 169, at 300 (noting that the agency was "dissuaded" by the Proxmire Amendment) [hereinafter GAO Report].

217 See GAO Report, supra note 216 , at 6.

218 Regulation of Dietary Supplements, 58 Fed. Reg. at 33,698-99 (June 18, 1993) (discussing the market prevalence of dietary supplements).

219 See Howard M. Rubin, Courts, Congress Re-examine Nondrug Products, 21 NAT'L L.J., July 5,1999 , at B8. 1997).

See Nutritional Health Alliance v. Shalala, 953 F. Supp. 526, 526 (Dist. Ct. S.D.N.Y.

221 See Christopher Smith, Supplements and the Feds, SAlT LAKE Trib., May 21, 2001, at A8.

222 See David C. Vladeck, Truth and Consequences: The Perils of Half-Truths and Unsubstantiated Health Claims for Dietary Supplements, 19 J. PUB. POL'Y \& MARKETING 132 (2000). For instance, dietary supplement companies marketed claims ranging from "Stone Free Kidney and Gall Formula" to "Fat Burners," which erroneously suggested effective treatments for serious afflictions. Id.

$223 \quad I d$.

224 Pub. L. No. 101-535, 104 Stat. 2353 (1990) (codified as amended at 21 U.S.C. §§ 301397).

225 For an expanded discussion of the NLEA, see Michael A. McCann, Economic Efficiency and Consumer Choice Theory in Nutritional Labeling, 2004 WIS. L. REV. 1161, 1187-91 (2004).

$226 \S 2,104$ Stat. at 2353-57 (codified as amended at 21 U.S.C. $\$ 343$ ).

227 See McCann, supra note 225, at 1187 (discussing $\$ 2,104$ Stat. at 2353-59).

228 See $\S 3,104$ Stat. at 2358. 
significant scientific agreement. ${ }^{229}$ Following passage of the NLEA in 1990, the FDA issued revised nutrition labeling regulations for food products to update the 1973 regulations, which had required disclosure of any vitamin, mineral, or nutrient. ${ }^{230}$ In general, the revised regulations require scientific agreement among qualified experts about the safety of ingredients in food products. ${ }^{231}$

The subject of dietary supplements received considerable attention in promulgating NLEA. ${ }^{232}$ Intriguingly, despite the long-standing feud between Congress and the FDA over dietary supplements, Congress declined to prescribe a substantive standard for dietary supplements in the NLEA. Rather, by instructing the FDA to propose dietary supplement regulations by 1991, Congress invited FDA clarity on dietary supplements. ${ }^{233}$ Like always, however, politics were not unimportant in Congress' willingness to delegate: It was thought that newlyappointed FDA Commissioner David Kessler, a former aide to Senator Orrin Hatch, would promote moderate and restrained regulatory impositions on the dietary supplement industry. ${ }^{234}$

Doubtless to the surprise of many, Dr. Kessler announced extensive plans for the FDA to "restore credibility and integrity" in the dietary supplement market. ${ }^{235}$ For instance, he proposed to ban many dietary ingredients as unapproved food additives. ${ }^{236}$ The hallmark of those plans, however, included consonant health claim standards for food and dietary supplement labels, with each requiring established scientific grounding and pre-market FDA approval. ${ }^{237}$ Significantly, at that time, the FDA interpreted such standards to mean that no dietary supplements were qualified to furnish health claims on their product labels. ${ }^{238}$ The regulations were set to take effect in November 1992, with a subsequent seven-month grace period for compliance.

Predictably, the proposed regulation rippled through the halls of Congress, as well as the offices of dietary supplement lobbying firms and public interest groups. On one hand, consumer groups praised the FDA, surmising that consumers of supplements should be accorded the same protection as consumers of food products. Likewise, the National Association of Attorney Generals swiftly passed a resolution

$229 \quad I d ; 21$ U.S.C. $\$ 343(\mathrm{r})(3)(\mathrm{B})(\mathrm{i})$.

$230 \quad 21$ C.F.R. $\$ 101.9(\mathrm{a})(1)(2004)$.

231 Until 1997, health claims required FDA premarket approval, which was based on "the totality of publicly available scientific evidence ... [that the claim is supported by] significant scientific agreement, among experts qualified by scientific training and experience." 21 U.S.C. $\S$ 343(r)(3)(B)(i). In 1997, the Food and Drug Administration Act was passed, which largely removed the requirement of FDA approval, but still mandated that claims for non-restauarant food be derived from "authoritative statements" of a scientific body. See McCann, supra note 225 , at 1189 .

See Gilhooley, supra note 168 , at 679.

233 See 21 U.S.C. $\S 343(\mathrm{r})(5)(\mathrm{D})$ (2000) ("A subparagraph (1)(B) claim made with respect to a dietary supplement of vitamins, minerals, herbs, or other similar nutritional substances shall not be subject to subparagraph (3) but shall be subject to a procedure and standard, respecting the validity of such claim, established by regulation of the Secretary").

234 See Smith, supra note 186.

235 Senator Hatch would later say that his former aide, Dr. Kessler "had been captured" by the FDA. ${ }_{236}$.

${ }_{236}$ See Hearing Before the Subcomm. On Health and Environment of the House Comm. on Energy and Commerce, 108th Cong. (2003) (remarks of David Kessler).

See NPR: Dietary Supplements and Regulations Pertaining to Them, (NPR radio broadcast, Apr. 19, 1999) (noting remarks from Dr. David Kessler, former head of the FDA) [hereinafter NPR Transcript].

${ }_{238}$ See Gilhooley, supra note 168, at 679. 
affirming the FDA's position, reasoning that such regulations would advance state health policies. ${ }^{239}$

On other hand, even the FDA recognized that its proposed regulations would upset the dietary supplement industry, holistic groups, and numerous elected officials. Indeed, consider language employed by the FDA to preface its proposed regulation: "The Agency recognizes that proposing the same standard for conventional food and dietary supplements is contrary to the view expressed by some members of Congress." 240 Almost immediately, holistic groups, which regarded higher standards as mere concessions to the pharmaceutical industry, and the supplement industry, which resented an arguably zealous FDA, pressured Congress to preempt implementation of the proposed FDA regulations with new legislation. ${ }^{241}$ Their positions were not entirely unfounded, as the Surgeon General and National Research Council had recently issued studies discouraging the treatment of dietary supplements as food products. ${ }^{242}$

Before the FDA regulations were implemented in November 1992, Congress passed the Dietary Supplement Act of $1992^{243}$ ("1992 Act"), which imposed a oneyear delay on regulatory implementation. ${ }^{244}$ Moreover, to promote distinction between food products and dietary supplements, the 1992 Act mandated that the FDA propose specific (and therefore different) rules for dietary supplements. ${ }^{245}$ By delaying regulatory implementation and by mandating a new set of proposed FDA regulations, the 1992 Act also served a tactical purpose: provide Congress more time to pass industry-friendly legislation.

In 1993, however, the FDA issued a controversial "Advance Notice of Proposed Rulemaking" ("Advanced Notice") that only further riled FDA critics in Congress, particularly those with close ties to herbal supplement manufacturers. ${ }^{246}$ Unabashedly, the FDA concluded that "many herbs have no known history of food use and, even without drug claims, are used for medical purposes. Many of these herbs have a history of use as traditional medicines in many countries outside of the United States." 247 The FDA also found a significant pattern of adverse effects associated with various herbal dietary supplements, ${ }^{248}$ thus motivating a renewed agency desire to curtail sale of hazardous herbal products. ${ }^{249}$ Moreover, less than one year later, a resolute, if perhaps dogmatic, FDA responded to the 1992 Act by proposing a strikingly familiar regulatory scheme: that dietary supplements and food products share the same regulatory treatment for health claims. ${ }^{250}$

239 See National Association of Attorneys General Summer Meeting, Resolution on Deceptive Claims in Dietary Supplement Labeling and Advertising, 49 FOOD \& DRUG REPORT 474 (1993).

240 See MILLER, supra note 204.

241 See NPR Transcript, supra note 237.

242 See William J. Kolasky, Jr., The Impact of the Food and Drug Administration's Reproposal on Vitamins, Minerals, and other Nutritional Supplements, 45 FOOD DRUG COSM. L.J. 639, 644-45 (1990).

${ }_{243}$ Dietary Supplement Act of 1992, Pub. L. No. 102-571, 106 Stat. 4491 (1992).

244 ld. at $\S 202(\mathrm{a})(1)$.

$245 \quad$ ld. at $\$ 202(\mathrm{a})(2)(\mathrm{A})$.

246 See Regulation of Dietary Supplements, 58 Fed. Reg. 33,690 (June 18, 1993).

247 Id. at 33,697 .

248 Id. at 33,698 (for example, the FDA noted that toxic hepatitis has been associated with the consumption of chaparral, a popular herbal supplement).

249 Id.

250 Food Labeling: General Requirements for Health Claims in Dietary Supplements, 58 Fed. Reg. 33,700, 33,700 (June 18, 1993). 


\section{E. Configuring Dietary Supplements as Food Additives: The War CONTINUES}

The FDA's characterization of certain dietary ingredients as food additives only further provoked the dietary supplement industry, as such characterization imposed more costly approval requirements under the FDCA. ${ }^{251}$ Indeed, consider the burdenshifting between a food additive, a presumptively unsafe product for which the processor bears the burden of demonstrating safety, and a GRAS dietary ingredient, a presumptively safe product for which the FDA bears the burden of proving it injurious to health. ${ }^{252}$ More specifically, by requiring that supplement manufacturers meet the food additive standard, the FDA compelled documentation that the scientific community considered the supplement safe. ${ }^{253}$ The cost of obtaining such documentation typically proved exorbitant, often entailing extensive research, 15 or years or more of data accumulation, and the wherewithal to absorb repeated and meaningful expenses inherent in FDA administrative proceedings. ${ }^{254}$ It is estimated that such costs would exceed $\$ 1,000,000$ per product, with many products ultimately failing to receive approval. ${ }^{255}$

Perhaps best illustrating this zeal, consider the FDA's attempted regulation of black currant oil ("BCO"), an extract from the seeds of the black currant berry and marketed as a dietary supplement because of its fatty-acid structure. ${ }^{256}$ The FDA contended that BCO was not GRAS and became a food additive when combined with the gelatin and glycerin used to form capsules. ${ }^{257}$ As a result, BCO capsules could not be marketed as dietary supplements without satisfying the more arduous food additive approval process. ${ }^{258}$ The FDA held this position even though gelatin and glycerin were used as preservatives, and even though BCO was not considered a food additive when vended in bottled liquid form. ${ }^{259}$

To the FDA's dismay, however, two U.S. Courts of Appeal disagreed with agency, finding that BCO comprised the sole dietary ingredient of BCO capsules and thus should have been considered a food itself rather than a food additive. Indeed, the courts deemed the capsules mere delivery mechanisms for BCO ingestion. ${ }^{260}$ Most alarming to the courts were the "common sense" implications of the FDA's position: "The proposition that placing a single-ingredient food product into an inert capsule as a convenient method of ingestion converts that food into a food additive

251 See Phil Wallace, Senate Increases Funding for Labeling Enforcement, FOOD CHEMICAL NEwS, Nov. 12, 2001, at 21. Senator Tom Harkin (D-IA) said of the FDA, "We admonish the agency not to wield the heavy hand it did for over three decades, the over-bearing attitude which led Congress to pass [DSHEA] so overwhelmingly in the first place." $I d$.

${ }_{252}$ See United States v. An Article of Food, 678 F.2d 735, 739 (7th Cir. 1982).

253 See Regulation of Dietary Supplements, 58 Fed. Reg. at 33,692 n.2.

254 See FDA Safeguards Against Improper Disclosure of Financially Sensitive Information: The Product Approval Centers, Final Report 162 (Nov. 14, 1991) reprinted in 33 FOOD CHEM. NEWS, Nov. 4, 1991, at 67.

255 See McNamara, supra note 181, at 343.

256 See United States v. Two Plastic Drums, 984 F.2d 814 (7th Cir. 1993).

257 See id. at 816 . The FDA's reasoning behind this structural argument rested in 21 U.S.C. \& $321(\mathrm{~s})$, with the agency surmising that the BCO became a literal "component" of food when combined with two other "components." Id.

258 See Stephen H. McNamara \& A. Wes Siegner, FDA has Substantial and Sufficient Authority to Regulate Dietary Supplements, 57 FOOD DRUG L.J. 15, 16 (2002); see also S. REP. NO. $103-410$, at 16 (Oct. 8, 1994) ("The cost to a manufacturer to prepare a food additive petition can run to $\$ 2$ million. FDA approval of a food additive petition typically takes from 2 to 6 years.").

${ }_{259}$ S. REP. NO. 103-410, at 16 (OCT. 8, 1994)

260 See United States v. 29 Cartons, 987 F.2d 33, $37-39$ (Ist Cir. 1993); Two Plastic Drums, 984 F.2d at 820 ; see also Noah \& Merrill, supra note 147 , at 346-47. 
perverts the statutory text, undermines legislative intent, and defenestrates common sense." "261 In fact, as commentators have noted, if the FDA's expansive interpretation of food additives had been deemed valid, other food products, including dietary supplements, might also have been considered food additives, thus shifting the burden of proving safety onto their processors. ${ }^{262}$

The FDA's desire to treat dietary supplements as food additives clearly threatened to impose greater production costs on dietary supplement makers and limit their capacity to promote unrealistic claims. ${ }^{263}$ Whether such stern treatment reflected excessive bureaucratic caution or appropriate protection remains a source of scholarly debate. ${ }^{264}$ Of greater certainty and perhaps symbolism, such treatment reflected a growing chasm between the FDA, Congress, and dietary supplement companies, and one that also appeared increasingly irreparable. ${ }^{265}$

\section{F. DIETARy SUPPlement HEATH \& EDUCATION ACT: INDUSTRY Wins WAR}

By the fall of 1994, the widening philosophical gulf between Congress and the FDA resulted in a legislative enactment crafted largely to the favor the dietary supplement industry: DSHEA. ${ }^{266}$ Though the proposal encountered initial opposition, ${ }^{267}$ it soon muted as the Nutritional Health Alliance, an industry group with close ties to both Democratic and Republican members of Congress, persuaded even the fiercest of Democratic critics to "speak softly."268 As a result, sufficient bipartisan support emerged, and, steered by the adroit stewardship of Senator Hatch, DSHEA quickly advanced through the legislative process, ${ }^{269}$ acquiring Senate approval on a voice vote with only a few senators present. ${ }^{270}$ Ostensibly, DSHEA sought to "supersede the [existing] ad hoc patchwork regulatory policy on dietary supplement" with one that removed "unreasonable regulatory barriers limiting or slowing the flow of safe products and accurate information to consumers.",271 By accomplishing more barrier removal than informational flow, DSHEA yielded significant latitude to dietary supplement companies in manufacturing and promoting their products, arguably at the expense of consumer safety.

\footnotetext{
26129 Cartons, 987 F.2d at 39.

262 See Noah \& Merrill, supra note 147, at 347.

$263 \quad I d$. at 349.
}

264 See, e.g., Elizabeth C. Price, Teaching the Elephant to Dance: Privatizing the FDA Review Process, 51 FOOD \& DRUG L.J. 651, 654-59 (1996) (arguing that FDA suffers from "an institutional culture that breeds risk avoidance and an autocratic style of regulation").

265 See Shalala, 953 F. Supp. at 528.

266 Dietary Supplement Health and Education Act of 1994, Pub. L. No. 103-417, 108 Stat. 4325 (codified as amended in scattered sections of 21 U.S.C.) [hereinafter DSHEA].

267 See Gayle Hanson, FDA and Vitamins: Bitter Pill or good Rx?, WASH. TIMES, Nov. 18, 2003, at A12 (detailing efforts of opposition on Capital Hill).

268 See Peter A. Vignulo, The Herbal Street Drug Crisis: An Examination of the Dietary Supplement Health and Education Act, 21 SETON HALL LEGIS. J. 200, 216-17 (1997). For instance, the Nutrition Health Alliance hired Anthony T. Podesta, former aide to Edward M. Kennedy (D-MA), the Chairman of the Senate Labor and Human Resources Committee, to spearhead the group's lobbying efforts. See Dante E.A. Ramos, Vitamin Makers Try a Dose of Lobbying, 25 NAT'L HEALTH J. 1879 (1993).

${ }_{269}$ The process began in the Senate Labor and Human Resources Committee, where DSHEA passed 12-5, over the objection of Chairman Edward M. Kennedy. See Smith, supra note 186.

270140 CONG. REC. S14,798-800 (daily ed. Oct. 7, 1994). 4325 (2004).

Congressional Findings of Fact, reprinted in Pub. L. No. 103-417 2 (1994), 108 Stat. 
First, DSHEA ensured that most dietary supplements would not require premarket testing for safety and efficacy. ${ }^{272}$ Indeed, DSHEA largely preempts the FDA's proposed rules to treat food products and dietary supplements identically. ${ }^{273}$ DSHEA also amends the FDCA to distinguish dietary supplements as non-food additives and, depending upon particular product claims, as non-pharmaceutical drugs. ${ }^{274}$ This is true even when dietary supplements contain ingredients identical to those used in food additives or pharmaceutical drugs. ${ }^{275}$

Equally important, DSHEA significantly expands the statutory definition of "dietary supplement" beyond essential nutrients. ${ }^{276}$ Specifically, DSHEA defines a dietary supplement as:

[any] product (other than tobacco) intended to supplement the diet that bears or contains one or more of the following ingredients:

(A) a vitamin;

(B) a mineral;

(C) an herb or other botanical;

(D) an amino acid;

(E) a dietary substance for use by man to supplement the diet by increasing the total dietary intake; or

(F) a concentrate, metabolite, constituent, extract, or combination of any ingredient described in clause (A), (B), (C), (D), or (E). ${ }^{277}$

As a result, substances such as fish oils, ginseng, garlic, and combinations thereof receive the comparatively relaxed regulatory treatment. This looser definition particularly benefits herbal supplement manufacturers, whose products often contain nonnutritive ingredients. ${ }^{278}$

DSHEA similarly benefits dietary supplement manufacturers by not requiring them to register with the FDA or to report adverse events from product usage, thus treating them akin to food manufacturers. ${ }^{279}$ The Public Health Security and Bioterrorism Preparedness and Response Act of $2002^{280}$ ("Bioterrorism Act of 2002"), however, provides the FDA with additional regulatory authority over both

272 Although there is no general requirement for manufacturers of dietary supplements to submit evidence of product safety to the FDA before marketing a product, there exists "a 75-day premarket notification requirement for manufacturers or distributors of dietary supplements that contain 'new dietary ingredients' that were not marketed in the U.S. before October 15, 1994, unless the supplement contains only ingredients that have been present without chemical alteration in the food supply as an article used for food." Center for Food Safety and Applied Nutrition Director Comments on Status of Dietary Supplements in U.S., State News Service: Hearing on Ten Years After the Implementation of DSHEA: The Status of Dietary Supplements in the United States, Before the House Comm. on Government Reform. Subcomm. On Human Rights and Wellness, 108th Cong., Mar. 23, 2004, available at LEXIS News Wire (statement of Robert E. Brackett, Ph.D., Director Center for Food Safety and Applied Nutrition, Food and Drug Administration, Department of Health and Human Services) [hereinafter Statement of Robert E. Bracket].

${ }^{273}$ DSHEA $\S 11$ (voiding 58 Fed. Reg. 33,690 (June 19, 1993)).

274 Id. at $\S 3$ (b) (codified as amended at 21 U.S.C. $\$ 321(\mathrm{~s})(6)(2000)$ ).

$275 I d$. at $\S 3(\mathrm{~b})(3)$ (codified as amended at 21 U.S.C. $\S \S 321(\mathrm{~s})(6), 321(\mathrm{ff})(3)(\mathrm{A})$ ); see also Joshua A. Beisler, Dietary Supplements and Their Discontents: FDA Regulation and the Dietary Supplement Health and Education Act of 1994, 31 RUTGERS L.J. 51 1, 515 (2000).

276 See Gilhooley, supra note 168 , at 682 .

277 DSHEA $\S 3$.

278 See Gilhooley, supra note 168 , at 682 .

279 See Statement by Robert E. Brackett, supra note 272.

280 Pub. L. No. 107-188, 116 Stat. 694 (2002) (codified in scattered sections of 42 U.S.C.). 
types of manufacturers, and it requires manufacturers to register their processing facilities. ${ }^{281}$ On the other hand, dietary supplements, like food products, may be removed from the market only if the FDA determines that they contain "poisonous or deleterious" substances. ${ }^{282}$ This standard has remained since 1906, as neither DSHEA nor other legislation has imposed a stricter one. ${ }^{283}$

DSHEA also affords wide latitude to dietary supplement label claims, treating them with only slightly greater scrutiny than food label claims. ${ }^{284}$ Indeed, provided supplement products bear a cursory label disclaimer, ${ }^{285}$ DSHEA exempts them from FDA pre-authorization of "structure/function" claims (such as "Calcium builds strong bones"), which involve the way in which a nutrient affects the function or structure of the body. ${ }^{286}$ More broadly, DSHEA enables supplement companies to:

(1) "claim[] a benefit related to a classical nutrient deficiency disease and disclose[] the prevalence of such disease in the United States";

(2) "describe[] the role of a nutrient or dietary ingredient intended to affect the structure or function in humans";

(3) "characterize[] the documented mechanism by which a nutrient or dietary ingredient acts to maintain such structure or function"; and

(4) "describe[] general well-being from consumption of a nutrient or dietary ingredient.",287

This discretion includes the capacity to promote a product's alleged "affect [on] the structure on function in humans," 288 as well as its capacity to "support a healthy heart," "protect cells from damage," and "improve the function of a comprised immune system," regardless of whether the product definitively performs such functions. ${ }^{289}$ From a practical perspective, supplement companies may use any language to promote the functional and structural benefits of their products, as long as the text is not misleading or false. ${ }^{290}$

On the other hand, DSHEA invited regulatory clarity on ingredient content and levels of vitamins and minerals appearing on product labeling. Beginning in March

$281 \quad 21$ U.S.C. $\S 350 \mathrm{~d}(\mathrm{a})(1)$ (Supp. 2002).

282 U.S.C. $\$ \S 342$ (a), (f) (Supp. 2002).

283 As noted by Professor Hutt, although DSHEA did clarify the "poisonous or deleterious" substance standard by providing that any food or supplement is only deemed to be adulterated if it may be injurious to health under the conditions of use recommended or suggested on the labeling, "this difference is of no practical importance because the Supreme Court had adopted a similar interpretation of the provision as early as 1914 and that decision has remained unchanged ever since." See Peter Barton Hutt, FDA Statutory Authority to Regulate The Safety of Dietary Supplements (draft of forthcoming article, Oct. 3, 2004, on file with author) (21 U.S.C. $\S 342(f)$ and United States v. Lexington Mill \& Elevator Co., 232 U.S. 399 (1914), respectively).

284 Labels on conventional food can make structure/function claims without any disclaimer.

28521 U.S.C. $\& 343(\mathrm{r})(6)(\mathrm{C})$ (stipulating that the product labels must include the following language: "This statement has not been evaluated by the Food and Drug Administration. This product is not intended to diagnose, treat, cure, or prevent any disease").

28621 U.S.C. $\S 343(\mathrm{r})(6)$. A structure/function claim is permitted so long as the FDA is notified, the manufacturer has substantiation that the claim is truthful and not misleading, and the product contains a disclaimer. The following disclaimer must accompany structure/function claims: "This statement has not been evaluated by the Food and Drug Administration. This product is not intended to diagnose, treat, cure or prevent any disease." Shalala, 953 F. Supp. at n.11 (citing 21 U.S.C. \& 343(r)(6)(C) (1994)).

$287 \quad 21$ U.S.C. $\S 343(r)(6)$.

$288 \quad 21$ U.S.C. $\$ 342(r)(6)$.

289 The product claims refer to products "CardiAll," "Liverite," and "Resist," respectively. See Specter, supra note 94.

${ }_{290}$ See Robert G. Pinco \& Paul D. Rubin, Ambiguities of the Dietary Supplement Health and Education Act of 1994, 51 FOOD DRUG L.J. 383, 385 (1996). 
1999, and pursuant to implementing FDA regulations, dietary supplement labels were required to display a "Supplement Facts" panel similar to the "Nutrition Facts" panel on most processed foods. ${ }^{291}$ These panels mandate a listing of all dietary ingredients present in a product, and when certain nutrients, such as Vitamin C, calcium, and iron, are present in significant levels, supplement manufacturers must provide the daily-recommended percentage. ${ }^{292}$

DSHEA also initially preserved the NLEA's more stringent standard for supplement (and food) health claims, including those pertaining to specific disease treatment. Indeed, in enacting DSHEA, Congress created the Commission on Dietary Supplement Labels ("DSHEA Commission") to identify optimal regulatory language for supplement health claims, particularly in comparison to food and drug health claims. The findings of the Commission were accorded significant weight, since DSHEA mandated that the FDA issue timely regulations in response to any Commission recommendation; failure to do so would have exempted all dietary supplements from the basic NLEA requirements. ${ }^{293}$

In response to Congress' directive, the Commission largely affirmed that health claims for dietary supplements, like those for food products, should require premarket approval based on significant scientific agreement. ${ }^{294}$ The Commission reasoned that consumers are likely to be as confused by supplement health claims as by food and drug health claims. ${ }^{295}$ Significantly, however, the Commission also endorsed greater involvement by outside experts in the FDA review process of supplement health claims. ${ }^{296}$ As discussed in this Article, the scope of the FDA health claim review process would prove unsettled for years to come, often resulting in uncertain signals for consumers assessing risk and benefit.

\section{POST DSHEA \& CONSUMER INTERACTION WITH DIETARY SUPPLEMENTS}

\section{A. Market Manipulation \& Consumer Uncertainty Through Legislative AMBIGUITY \& ADMINISTRATIVE VARIANCES}

Once signed by President Clinton, DSHEA became a rare political volleyball without discernable partisan affiliation. Indeed, supporters from across the spectrum championed it as a victory for consumer freedom, populist protection, and

291 See Food Labeling; Statement of Identity, Nutrition Labeling and Ingredient Labeling of Dietary Supplements, 60 Fed. Reg. 67,194, at 67,205 (Dec. 28, 1995) (codified at 21 C.F.R. pt. 101); see also 62 Fed. Reg. 49,826 (Sept. 23, 1997) (codified at 21 C.F.R. pt. 101) (explaining that "supplement facts" was chosen instead of "nutrition facts" because with "nutrition facts . . the information presented, at least in part, is about nutrition, or because these products are marketed for their nutritional value. The nutritional value of a particular product does not determine whether it is a dietary supplement or a conventional food. Many dietary supplements contain many DV-nutrients; many contain none.").

${ }_{292}$ See Overview of Dietary Supplements, FDA, Jan. 3, 2001, at http://vm.cfsan.fda.gov/ dms/ds-oview.html; 62 Fed. Reg. 49,825, at 49,849 (Sept. 23, 1997) (codified at 21 C.F.R. pt. 101).

${ }_{293}$ See DSHEA $\S 12(\mathrm{e})(3)$; see also Gilhooley, supra note 168, at n. 87 (explaining the significance of the Commission on FDA rulemaking).

${ }^{294}$ See REPORT OF THE COMM'N ON DIETARY SUPPLEMENT Labels at 30 (Nov. 1997), available at http://www.health.gov/dietsupp/ .

295 Id. at 34.

296 Id. at 35; see also FDLI meeting reviews US dietary supplements legislation, 2 NutraceutiCALS INT'L (1997) (noting how the DSHEA Commission recommended that the FDA improve the process by encouraging external input from scientists and governmental experts). 
preventative medicine. For instance, Senator Tom Harkin predicted that, by promoting supplements' preventive qualities, DSHEA would diminish national healthcare costs. ${ }^{297}$ Similarly buoyant, President Clinton reveled in the replacement of a regulatory framework where "agencies of government charged with promoting the food supply and the rights of consumers have paradoxically limited the information to make healthful choices in an area that means a great deal to over 100 million people., $" 298$

Others, however, viewed DSHEA more guardedly. Most telling, the Center for Science in the Public Interest forecasted "America's Second Age of Quackery."299 In other quarters, DSHEA became emblematic of an increasingly de-regulated society, where the interests of consumers are dwarfed by those of large industries. ${ }^{300}$ Perhaps DSHEA's greatest critics were FDA administrators, who were said to regard it as a detrimental reversal of effective regulatory philosophies-a viewpoint which may have diminished their initial commitment to regulatory implementation. ${ }^{301}$

Notwithstanding rhetorical flourish, DSHEA has discernibly promoted a regulatory framework whereby product effectiveness and risk are largely unknown to consumers. ${ }^{302}$ Indeed, since passage of DSHEA, supplements have increasingly fallen under the regulatory radar. ${ }^{303}$ Though some consumers uncover relevant information through informal research methods, such as Internet searches or consultations with medical clinicians, the vast majority remains uninformed, typically until a group of product users suffers health complications that generate media attention or, more seldom, FDA action.

Along those lines, many Americans express obliviousness to the considerable regulatory variances among food, drugs, and dietary supplements. Indeed, most are unaware that, while pharmaceutical drugs receive extensive FDA pre-market testing to verify safety and efficacy, dietary supplements do not. ${ }^{304}$ Such unawareness likely correlates to consumer linkage of drugs and supplements as functionally akin products, with both presumptively designed to sustain or improve the state of one's health. $^{305}$ Consumer expectations, therefore, suggest that efficacious regulation would treat dietary supplements more like drugs than food.

297140 Cong. Rec. S14780 (daily ed. Oct. 7, 1994).

298 DSHEA: Statement by President Clinton Upon Signing S. 784, 1995 U.S.C.C.A.N. 3523-1

(Oct. 25, 1994). President Clinton also heralded how "manufacturers, experts in nutrition, and legislators, acting in a conscientious alliance with consumers at the grassroots level, have moved successfully to bring common sense to the treatment of dietary supplements under regulation and law." Id.

299 See Smith, supra note 186.

300 See Gilhooley, supra note 168, at 666 (noting that "the term 'being DSHEAed' has become a popular byword for deregulation"); see also Nestle, supra note 147, at 233 (describing concerns of potential quackery generated by DSHEA).

${ }_{301}$ See NPR Transcript, supra note 237 (quoting Annette Dickinson, head of the Supplement Trade Association, the Council for Responsible Nutrition.); see also Robert G. Pinco \& Todd H. Halpern, Guidelines for the Promotion of Dietary Supplements: Examining Government Regulation Five Years After Enactment of the Dietary Supplement Health and Education Act of 1994, 54 FOOD DRUG L.J. 567, 579 (1999) (noting that DSHEA surprised the FDA).

${ }_{302}$ See Sara Schulman, Addressing The Potential Risks Associated with Ephedra Use, 118 PUB. HEALTH REP. 487, 492 (2003).

303 See NPR Transcript, supra note 237 (quoting Annette Dickinson, head of the Supplement Trade Association, the Council for Responsible Nutrition.).

304 See Arthur P. Goldman, Unregulated Herbal Remedies-an Accident Waiting to Happen, CHI. TRIB., Dec. 24, 2002, at C19 (Professor Goldman noting that most Americans are unaware that dietary supplements do not receive premarket testing).

305 See supra at Part III.C. 
Regulatory variances triggered by DSHEA have also influenced industry behavior, particularly in regards to manufacturers' bargaining leverage with the FDA. This is especially evident among manufacturers whose products might be classified as food, drugs, or dietary supplements. Since DSHEA endorses a minimalist regulatory approach to supplements, manufacturers are encouraged to attempt to classify their products as supplements and thus avoid pre-market testing, required disclosures, and prohibition on certain ingredients.

To best illustrate this phenomenon, consider Johnson \& Johnson's efforts to market Benecol, a margarine that may lower cholesterol levels, as a dietary supplement rather than as a food or drug. ${ }^{306}$ The FDA disagreed with such classification, finding that Benecol's active ingredient, a plant sterol inhibiting cholesterol absorption, represents an unapproved food additive that requires FDA premarket approval. ${ }^{307}$ After lengthy negotiation, the FDA and Johnson \& Johnson agreed to a comprise whereby Benecol would be designated as a food rather than a dietary supplement but would be GRAS and not subject to premarket approval. ${ }^{308}$ This outcome illustrates how, even when supplement manufacturers fail to receive favorable classification under DSHEA, they appear emboldened by its presence, and thereby gain a certain degree of negotiating leverage with the FDA that improves their probability of lessened regulatory costs. For that later reason, supplement manufacturers may project greater return on more "risky" products.

Consumer knowledge of supplement effectiveness and risk also appears constrained by the uncertain regulatory treatment of supplement health claims, which characterize the relationship of any substance to a disease or health-related condition. ${ }^{309}$ Indeed, discerning "health claims" from significantly less regulated "structure/function claims" has sometimes proven unpredictable. Though certain claims unambiguously comprise health claims, such as "fiber cures cancer," appear murkier. For instance, consider the claim that a supplement "promotes nonsuicidal feelings." 311 Notably, this claim omits mention of specific disease, though one might reasonably deduce that the product treats depression or similar mental illness.

The murkiness of claim distinctions also promotes market manipulation of labeling. Since passage of DSHEA, dietary supplement companies have often secured and intensely promoted the "endorsement" of physicians, chiropractors, or "nutrition experts." 312 This is not surprising, since studies confirm that, "to the modern consumer, information labeled as 'scientifically proven' often assumes a

306 See Pat Kendall, Benecol: Cholesterol-Fighting Margarine, Colo. ST. U. CoOPERATIVE EXTENSION, Mar. 24, 1999, at http://www.ext.colostate.edu/pubs/columnnn/nn990324.htmI.

${ }_{307}$ See Illene Ringel Heller, Functional Foods: Regulatory and Marketing Developments, 56 FOOD DRUG L.J. 197, 210-11(2001).

$308 \quad$ Id.

309 See 21 C.F.R. § 101.14(a)(1) (2005); Deborah Pines, Time Limit on FDA Vitamin Review, N.Y.L.J., Feb. 6, 1997, at 1. Such review could last an indeterminable period, particularly since the FDA offered no fixed deadline to promulgate final regulations for a health claim. 21 C.F.R. $\S$ 101.14(a)(1).

310 21 C.F.R. $\$ 101.14(a)(1)$.

311 See Gilhooley, supra note 168 (mentioning this language as a useful illustration of DSHEA's definitional murkiness).

${ }_{312}$ See Patrick B. Massey, Be Wary of Supplements Labeled 'Proprietary Blend', CHI. DAILY HERALD, Feb 16, 2004, at 5 (Dr. Massey is medical director for alternative and complementary medicine for Alexian Brothers Hospital Network). 
posture of "mystic infallibility.",313 To illustrate, the manufacturer of Cartilade, a dietary supplement made of shark cartilage, labeled its product with pictures of a physician commonly associated with the claim that shark cartilage cures cancer. ${ }^{314}$ Moreover, the mere allowance of "structure/function claims" appears to encourage undesirable word parsing. For instance, a supplement label would include a "health claim" if it claimed to reduce the onset of cataracts but would comprise a mere "structure/function" claim if it asserted that the supplement "promotes healthy vision." 315 Though the latter claim entails less specificity, a consumer may easilyand mistakenly-assume the two claims represent similar therapeutic value.

The adequacy of dietary supplement consumer information appears likewise disturbed by ongoing discord over the phrase "significant scientific agreement among experts," which is required for health claim approval. Such discord particularly relates to the First Amendment and its interplay with health claim standards. Indeed, some contend that commercial speech jurisprudence offers the most salient justification for consumer access to dietary supplements, since First Amendment commercial speech cases tend to favor informed consumer choice over government imposed limitations. ${ }^{316}$

These ideas were tested in Pearson v. Shalala,${ }^{317}$ where a dietary supplement manufacturer challenged the FDA's refusal to authorize health claims for failing to demonstrate the requisite significant scientific agreement. ${ }^{318}$ On appeal, the U.S. Court of Appeals for the District of Columbia upheld the concept of premarket approval for health claims ${ }^{319}$ but invalidated the specific FDA standard since it imposed a higher standard than permitted by the First Amendment. ${ }^{320}$ Indeed, the court noted that in enacting DSHEA, Congress intended to broaden consumer freedom in choosing safe supplements. ${ }^{321}$ Moreover, in holding that supplement health claims comprise qualified commercial speech and thus warrant constitutional protection, the court directed the FDA to allow statements of preliminary scientific findings. In 2003, the FDA announced that it would consider "qualified health claims," which comprise more guarded claims based on less than significant scientific agreement. ${ }^{322}$ Nevertheless, the FDA continues to contemplate how to best implement Pearson, leaving a certain degree of uncertainty for dietary supplement consumers as to the extent to which they can rely on supplement health claims.

Even when health claims are indisputably discernable, the FDA possesses limited purview over dietary supplement advertising. As stipulated in the FDCA, FDA authority to regulate claims is restricted to product label content, which

313 See Charles J. Walsh \& Marc S. Klein, From Dog Food to Prescription Drug Advertising: Litigating False Scientific Establishment Claims Under the Lanham Act, 22 SETON HALL L. REV. 389, 392 (1992).

314 See United States v. Lane Labs-USA, Inc., 324 F. Supp. 2d 547 (D.N.J. 2004).

315 See Sally Squires, High Irony: New Supplement Labels are Short on Facts, WASH. POST, Mar. 7,2000, at Z14.

316 See Tom Valluck, Keeping Dietary Supplement Regulations Slim and Fit: Finding a Healthy Balance between Paternalism and Consumer Choice, 2 GEO. J.L. \& PUB. POL'Y 285, 300 (2004) (citing Virginia State Bd. of Pharmacy v. Virginia Citizens Consumer Council, Inc., 425 U.S. 748 (1976); Pearson v. Shalala, 164 f.3d 650, 658 (D.C. Cir. 1999)).

31714 F. Supp. 2d 10, (D.D.C., 1998), rev'd 164 F.3d 650 (D.C. Cir. 1999).

$31814 \mathrm{~F}$. Supp. $2 \mathrm{~d}$ at 10.

319 Pearson, 164 F.3d at 656.

$320 \quad$ Id. at 657 .

$321 \quad$ Id. at 658 .

322 See supra pp. 248-49. 
includes packaging, inserts, and other materials distributed at the point of sale. ${ }^{323}$ In contrast, dietary supplement advertisements in books, magazines, mailings, infomercials, and other television and radio commercials fall under the jurisdiction of the Federal Trade Commission ("FTC") and its controlling law, the Federal Trade Commission Act ("FTC Act"). ${ }^{324}$ As a result, health claims in those settings escape the purview of the FDA.

For a moment, consider variances between the FDA's and FTC's treatment of supplement claims, and how such variances affect consumer information. While manufacturers largely escape pre-market scrutiny of product label claims, FTC standards require them to substantiate all performance, efficacy, and safety claims used in advertising before releasing those claims to the public, and related claims must be based on "competent and reliable scientific evidence." 325 Consequently, consumers may internalize disparate messages for the same product, thus potentially leading to confusion. Given optimism bias and other cognitive biases, it is also plausible that many consumers might discount the more constrained advertising information and accord greater weight to extravagant label claims. ${ }^{326}$ In such a setting, supplement manufacturers possess incentive to manipulate biases to lower consumer appreciation of supplement risks. ${ }^{327}$ Perhaps that explains why many supplements do not contain ingredients listed on the label or contain ingredients that are not listed. ${ }^{328}$

Cooperation between the FDA and FTC in regulating supplement claims has improved in recent years, however, thus resulting in more stringent and proximate standards. Indeed, since a 1971 inter-agency liaison agreement, the FDA and FTC have expressed a willingness to cooperate on dietary supplement regulation. ${ }^{329}$ In fact, the FTC now accords "significant deference" to the FDA's scientific expertise, even when a claim is subject to joint jurisdiction. ${ }^{330}$ Similarly, the FTC requires

323 See generally 21 U.S.C. $\$ \S 321-393$ (2000); see also 21 U.S.C. $\S 321(\mathrm{~m})$ (defining the term "labeling"); Pinco \& Halpern, supra note 301, at 579 (distinguishing labeling from advertising).

${ }_{324}$ See Federal Trade Commission Act, 15 U.S.C. $\$ \$ 45(\mathrm{a}), 52,55$ (1972 \& West Supp. 2004) (prohibiting unfair or deceptive acts or practices in or affecting commerce, and false advertisements for food, drugs, devices, services, or cosmetics in or affecting commerce); see also 59 Fed. Reg. 395, 409 (Jan. 4, 2004); FTC DIETARY SUPPLEMENTS ADVERTISING GUIDE FOR INDUSTRY (1998) (defining advertising).

${ }_{325}$ See Substantiation Policy Statement, appended to Thompson Medical Co., 104 F.T.C. 648, 839 (FTC, 1984); Deception Policy Statement, Letter Dated Oct. 14, 1983 from Commission to Chairman John D. Dingell, appended to Cliffdale Associates, Inc., 103 F.T.C. 110,174 (1984); 15 U.S.C. $\S \S 52,55(2000)$ (instructing advertisers to provide substantiated and accurate product information).

${ }_{326}$ This deduction appears consonant with research conducted by Dr. Kenneth Walker of Toronto General Hospital, as he found that dietary supplement users tend to be most attracted to certain cue words on labels, such as "natural" and "organic." See Kenneth Walker, Understand the Facts about Ginkgo Biloba, CHI. SUN-TIMES, Apr. 2, 2000, at 8.

$327 \quad$ See generally, Hanson \& Kysar, supra note 55, at 1427.

$328 \quad$ See supra p. 228.

329 See FTC-FDA Liaison Agreement, 4 Trade Reg. Rep. (CCH) PP9851-52 (1971); see also In the Matter of Regulations on Statements Made for Dietary Supplements Concerning the Effect of the Product on the Structure or Function of the Body; Proposed Rule, Comments of the Staff of the Bureau of Consumer Protection of the Federal Trade Commission, Docket No. 98N-0044, Aug. 27, 1998 "Their shared jurisdiction means that the two agencies coordinate closely to ensure that their actions are consistent to the fullest extent feasible given the statutory authority of each"); see also Sarah E. Taylor \& Harold J. Feld, Promoting Functional Foods and Nutraceuticals on the Internet, 54 FOOD DRUG L.J. 423, 440-41 (1999) (explaining cooperation between the FDA and FTC in regulating dietary supplement claims on the Internet).

${ }_{330}$ See FTC Enforcement Policy Statement on Food Advertising, § III(A)(1) (May, 1994), available at http://www.ftc.gov/bcp/policystmt/ad-food.htm. 
extraordinary evidence for health claims that either were rejected by the FDA or are awaiting approval. ${ }^{331}$ As discussed in Part B, misleading or unsubstantiated health claims in supplement advertising comprise a burgeoning part of the FDA and FTC's collaborative enforcement agenda. ${ }^{332}$ In turn, consumers may benefit from decreased cognitive biases.

\section{B. CONSUMER DisRuptions through AdVERSE EVENT REPORTING}

With relatively minimal pre-market testing for the safety and efficacy of dietary supplements, one might presume stringent standards once those products enter the market. Such a presumption would prove largely inaccurate. Once dietary supplements enter the market, the FDA monitors them through an adverse event reporting system ("AER"). AER consists of voluntary and confidential reporting, primarily from industry participants, health care providers, and consumers. ${ }^{333}$ Reporting may occur when an undesirable symptom is detected in an exposed individual or a group of product users, though no established surveillance standard exists to ensure reporting. ${ }^{334}$ In the event of a report, the FDA may investigate, after which they may pursue enforcement action, which can entail formal mechanisms (e.g. seizure; injunction) or informal ones (product recall; detention; warning letter). ${ }^{335}$

The lack of mandatory AER reflects perhaps the greatest defect of DSHEA, particularly when viewed in the prism of consumer information. Indeed, the inspector general for the Department of Health and Human Services estimates that the system reveals less than 1 percent of actual adverse reactions to dietary supplements. ${ }^{336}$ Equally troubling, the FDA lacks the resources to expeditiously review many of those reported adverse-reactions. ${ }^{337}$ Instead, the agency often has to play "catch-up" to emerging problems, a predicament compounded by the sheer proliferation of supplements on the market. ${ }^{338}$

The absence of pre-market testing and labeling guidelines only further illuminates the defects inherent in AER. To illustrate, consider the plight of ephedra weight-loss supplements in the American economy. Ephedra weight-loss supplements derive from the desert plant "Ephedra equisetina," which, since at least

331 See Pinco \& Halpern, supra note 301 , at 581.

332 See The Food and Drug Law Institute's 45th Annual Educational Conference Keynote Addresses, 57 FOOD DRUG L.J. 227, 239 (2002) (noting comments by Shelia F. Anthony, Commissioner of the U.S. Trade Commission).

${ }_{333}$ See FDA Backgrounder, How FDA Handles Problem Reports (Aug. 2003), available at http://www.fda.gov/opacom/backgrounders/report.html.

334 See Panel Offers Recommendations for Monitoring Adverse Events from Dietary Supplements, Life Sciences Research Office (Nov. 15, 2004), available at http://www.innovationsreport.de/html/reports/medicine_health/report-36264.html.

335 See Department of Health and Human Services, Office of the Inspector General, Adverse Event Reporting for Dietary Supplements: An Inadequate Safety Valve, OEI-01-00-00180, at 16 (Apr. 2001) (quoting Annual Industry Overview 2000, NUTRITION BUS. J., at 4).

S36 John A. McDonald, Dietary Aids Facing Scrutiny, HARTFord Courant, May 5, 2003, at $\mathrm{Al}_{33 \%}$

337 See Department of Health and Human Services, Office of the Inspector General, supra note 335 , at 16 .

338 This viewpoint is often expressed by FDA administrators. For instance, Christine Taylor, director of the FDA's Office of Nutritional Products, Labeling and Dietary Supplements, finds "the government does bear a considerable burden in post-marketing world." McDonald, supra note 336. 
3000 B.C. ${ }^{339}$ has been used in China as a stimulant and bronchodilator under its traditional name "Ma huang." 340 Ephedra has also been routinely misused as a herbal substitute for hallucinogenic amphetamine MDMA, or "ecstasy." 341 It has also been marketed in tea form, usually to treat patients with asthma and respiratory conditions, ${ }^{342}$ or, less often, to "cure" sexually transmitted diseases. ${ }^{343}$

In the United States, ephedra has been used primarily to stimulate weight loss and boost athletic performance. ${ }^{344}$ From 1993 to 2003, the FDA received 2,277 adverse event reports from ephedra users, with such symptoms as nausea, vomiting, anxiety, hypertension, tremors, and palpitations commonly noted. ${ }^{345}$ Far less frequently, use of ephedra has been associated with heart attacks, seizures, stroke, and death. ${ }^{346}$

Beginning in 1996, several states began to enact requirements for ephedra product labels in response to growing concerns over ephedra's safety. ${ }^{347}$ Those requirements mandated warnings be placed on ephedra supplement labels. Following the well-publicized, ephedra-related death of Baltimore Orioles pitcher Steve Belcher in $2003,{ }^{348}$ the FDA proposed that warning language be mandated on all ephedra supplement labels. ${ }^{349}$ In December 2003, the FDA ordered the removal of all ephedra supplements from the market, concluding that supplements containing ephedrine alkaloids presented an unreasonable risk of illness or injury. ${ }^{350}$ By that time, ephedra had been linked to 155 deaths and 16,000 adverse reactions. ${ }^{351}$ Notably, however, the FDA imposed no restriction on the sale of conventional foods

339 See FDA Hires Contractor to Handle Information Requests in its Adverse Events Reports AER System, FOOD CHEMICAL NEWS, June 7, 1999 (citing remarks by Daniel Mowrey of the American Phytotherapy Research Laboratory).

340 See Jun P. Tagalog, P3.6B Worth of Illegal Drugs Seized in Cebu, BusinessWorld, Mar. 18,2004 , at 12 .

341 Id.

${ }^{342}$ Interview with Dr. Andrew Weil, CNN TRANSCRIPTS, Mar. 20, 2004, available at LEXIS News Library, CNNTRN file (citing comments by Dr. Weil, director of the Integrated Medicine Program at the University of Arizona).

${ }_{343}$ Andrew Chevallier, The EnCyClopedia of Medicinal Plants (1996) (noting that in the 1800 s, ephedra was thought to cure gonorrhea and syphilis).

344 See Schulman, supra note 302.

345 U.S. General Accounting Office, Dietary Supplements Containing Ephedra: Health Risks and FDA's Oversight, Testimony before the House Subcommittee on Oversight of and Investigations (July 23, 2003), available at http://www.gao.gov/new.items/d031042t.pdf.

346 See Schulman, supra note 302.

347 Id.

348 Brody Mullins, Ephedra Battle Heats Up, Roll CALL, Mar. 12, 2003, at 1. available at LEXIS, News Library, ROLLCL file.

${ }_{349}$ U.S. Department of Health and Human Services, Dietary Supplements Containing Ephedrine Alkaloids; Reopening of the Comment Period, Docket no. 95N-0304, Feb. 28, 2003, available at http://www.fda.gov/OHRMS/DOCKETS/98fr/95n-0304-npr0003.pdf (including the following: "WARNING: Contains ephedrine alkaloids. Heart attack, stroke, seizure, and death have been reported after consumption of ephedrine alkaloids. Not for pregnant or breast-feeding women or persons under 18. Risk of injury can increase with dose or if used during strenuous exercise or with other products containing stimulants (including caffeine). Do not use with certain medications or if you have certain health conditions. Stop use and contact a doctor if side effects occur.").

350 Lester M. Crawford, Remarks of the Acting FDA Commissioner: FDLI's 47th Annual Conference, 59 FOOD DRUG L.J. 201, 206 (2004). After a three-month grace period, ephedra became an adulterated food as well as an unapproved and misbranded drug in February 2004. Final Rule Declaring Dietary Supplements Containing Ephedrine Alkaloids Adulterated Because They Present an Unreasonable Risk, 69 Fed. Reg. 6788 (Feb. 11, 2004) (to be codified at 21 C.F.R. pt. 119) (declaring dietary supplements containing ephedrine alkaloids adulterated because they present an unreasonable risk of illness or injury).

351 Virginia Anderson, Risky Ephedra Banned, ATLANTA J. CONST., Dec. 31, 2004, at 1 A. 
containing ephedra, such as herbal tea. ${ }^{352}$ Critics immediately complained of undue influence by the pharmaceutical industry and claimed that the vast majority of persons using ephedra encountered no discernable side-effects while perceiving significant bodily enhancement. ${ }^{353}$ Nevertheless, the FDA, along with federal law enforcement agencies, have since employed great efforts to remove ephedracontaining dietary supplements from the open market. ${ }^{354}$

Though media reports have often characterized ephedra as "deadly,",355 actual harm inflicted by the substance remains a source of debate. Clinical studies generally confirm a relationship between ephedra use and negative health consequences, ${ }^{356}$ although a significant minority suggests a less certain nexus, particularly when ephedra is used in recommended doses. ${ }^{357}$ Indeed, NVE Pharmaceuticals of New Jersey, the maker of the ephedra supplement called "Stacker 2," sued the FDA in March 2004, contending that the agency lacked proof that the stimulant is dangerous when used as directed. ${ }^{358}$ Recent case law strengthens this latter viewpoint. In Nutraceutical Corporation v. Crawford, ${ }^{359}$ the U.S. District Court for the District of Utah ruled that low-dose ephedra products do not present unreasonable risk or danger to consumers. ${ }^{360}$ Pending possible appeal, Nutraceutical Corporation dictates the removal of the FDA ban on low-dose ephedra products, though such a ban remains in effect for ephedra products of higher dose. ${ }^{361}$ Nevertheless, many in the scientific community insist that consumption of ephedra often proves harmful. Consider, for instance, a recent study published in the Annals of Internal Medicine, which claims that, although ephedra comprised less than one percent of the herbal supplement market from 1993 to 2002, it accounted for 64 percent of adverse reactions to such supplements. ${ }^{362}$

Of more certain concern is staggering evidence that ephedra manufacturers concealed the vast majority of consumer complaints. Indeed, two of the leading manufacturers, E'ola and Metabolife, failed to voluntarily report over 15,000 complaints, over ten percent of which involved deaths, heart attacks, strokes,

352 Phil Wallace, Court Challenge Seeks to Overturn FDA's Ban Reasoning, FoOD CHEMICAL NEWS, Dec. 13, 2004, at 12.

$353 \quad$ Id.

354 Most recently, in November 2004, the United States Attorney for the Southern District of Texas in U.S. District Court in Houston filed a complaint charging that VITERA-XT, an ephedracontaining dietary supplement marketed by Houston-based Asia MedLabs, Inc., represents an adulterated food as well as an unapproved and misbranded drug which presents an unreasonable risk of illness or injury. FDA Acts to Remove Ephedra-Containing Dietary Supplements From Market, FDA Press Releases, Nov. 23, 2004, available at LEXIS News Library, ALLNEWS file.

355 See, e.g., Jennifer Heldt Powell, Feds Circle Date for Ephedra Ban, Boston Herald, Feb. 7,2004 , at 30 .

${ }_{356}$ See, e.g., Christine A. Haller \& Neal L. Benowitz, Adverse Cardiovascular and Central Nervous System Events Associated with Dietary Supplements Containing Ephedra Alkaloids, $343 \mathrm{~N}$. ENGL. J. MED. 1833-38 (2000); D. Samenuk et al., Adverse Cardiovascular Events Temporally Associated with Ma Huang, an Herbal Source of Ephedrine, 77 MAYO CLIN PROC 12-16 (2002).

${ }_{357}$ See, e.g., C.N. Boozer et al., Herbal Ephedra/Caffeine for Weight Loss: $A$ 6-Month Randomized Safety and Efficacy Trial, 26 INT'L J. OBESITY 610 (2002).

358 Health Highlights, CONN. POST, Apr. 12, 2004.

359 No. 2:04CV409 TC, 2005 WL 852157 (D. Utah Apr. 13, 205).

$360 \quad$ ld.

361 See Penni Crabtree, Experts Debating Scope of Decision, SAN DIEGo TRIB., Apr. 16, 2005, at $\mathrm{Cl}$ (citing remarks by Kimberly Rawlings, an FDA spokeswoman). At the time of this writing, the Acting U.S. Solicitor General, Paul D. Clement, is considering whether to appeal.

${ }_{362}$ See Stephen Bent et al., The Relative Safety of Ephedra Compared with Other Herbal Products, 138 ANNALS AM. MED. 1006 (2003). 
seizures, chest pains, and heart rhythm disturbances. ${ }^{363}$ Such behavior appears consonant with manufacture incentive to distort cognitive biases and lower appreciation of product risks. ${ }^{364}$ The lack of regulatory deterrence also likely encouraged such behavior: The FDA's decision to remove ephedra represented the first time the FDA has ordered a dietary supplement pulled from the market since passage of DSHEA. ${ }^{365}$

\section{Contrasting American Treatment of Dietary Supplements to European Dietary Supplement Regulations and Private ENForcement MECHANISMS}

The relaxed regulatory treatment of dietary supplements appears striking when compared to the regulatory treatment of those products in other communities. This is especially detectable when observing the treatment of dietary supplements within the European Union ("EU"). Indeed, the Commission of the European Community requires "results of tests and trial on quality, safety and efficacy" of each supplement before the supplement can enter the EU's stream of commerce. ${ }^{366}$ Moreover, the EU recently passed the similarly restrictive Directive 2002/46/EC ("Directive"), which establishes maximum permissible doses for vitamin and mineral supplements and harmonized rules for product labeling. ${ }^{367}$ Such labeling requirements include the following: a stern warning of health risks for excess usage; the comment "This is not a medicinal product"; and an admonition that the product be stored out of the reach of young children. ${ }^{368}$ The Directive, which will be implemented by August 2005, also prohibits a wide array of supplement ingredients, including Vitamin $E$ and the mineral boron, which is commonly contained in supplements designed to advance women's health. ${ }^{369}$

The "Precautionary Principle" in part explains disparities in governmental regulation of dietary supplements in Europe and the United States. The Principle, which posits that preventative measures should be employed whenever there exists inconclusive scientific information or indications of harm from a particular behavior,

363 See Dietary Supplement Safety: Hearing Before the Senate Governmental Affairs Subcommittee on Oversight of Government Management, FED. DOC. ClEaRING House Cong. TESTIMONY, June 8, 2004 (testimony of Mr. Charles Bell Program Director, Executive Office, Consumer Reports (available at LEXIS, Nexis Library, CNGTST file.

364 See Hanson \& Kysar, supra note 55.

365 See Judy Sarasohn, A Departure from the Proscribed Path, WASH. Post, Jan. 22, 2004, at A23.

366 COMMISSION OF THE EUROPEAN COMMUNITY, Proposal for a Directive of the European Parliament and of the Council Amending the Directive 2001/83/EC As Regards Traditional Herbal

Medicinal Products
http://pharmacos.eudra.org/F2/pharmacos/docs/Doc2002/janv/com2002_1_en.pdf.

367 Long Wait Ahead For EU Supplements Industry on Maximum Doses, NuTRACEUTICALS INT'L, July 1, 2004 (noting that the European Union is now negotiating tolerable upper intake levels for the substances, and that process will continue until April 2005), available at LEXIS, News Library, NUTINT file. However, the European Court of Justice recently ruled that classifying dietary supplements as medicines if they contained more than one or three times the Recommended Daily Allowance for the relevant vitamins or minerals constituted a barrier to the free movement of goods across the EU. Id.

${ }_{368}$ Sidley Austin Brown \& Wood LLP, International National Products Regulation Q\&A: What Effect do They Really Have on the U.S.?, available at http://www.nnfa.org/services/government/pdf/Codex_EUdir.pdf (last visited Jan. 8, 2005).

369 Kathrin Jungbeck, Food Supplements Directive Set to Overhaul Europe, EuROMONITOR INT'L, June 15, 2004, available at http://www.euromonitor.com/article.asp?id=3258 (last visited Jan. $8,2004)$. 
has achieved far greater salience within European countries than in the United States. ${ }^{370}$ In essence, the Principle endorses a risk-averse philosophy to product availability within free markets, suggesting that such products should not be introduced until they are proven safe. ${ }^{371}$ Although "risk" is not prescribed absolute value in precautionary principle assessments, ${ }^{372}$ manufacturers bear a far greater burden when convincing policy-makers of product safety, particularly since product benefit receives diminished priority. ${ }^{373}$

The contrasting philosophy of tolerable risk found in European dietary supplement policies accentuates the industry-accommodating features of DSHEA. Indeed, by imposing discernibly less taxing requirements on manufacturers, DSHEA evinces greater policy worth in consumer access to products than in product efficacy or consumer safety. ${ }^{374}$ DSHEA also appears to reflect normative variances between European and American consumer protection ideals: it is thought that European preference for the Precautionary Principle manifests a broader desire for risk-utility analysis, while even American consumer advocates often endorse a less-protective "consumer expectation standard," which considers effect on "the reasonable consumer." ${ }^{375}$ These conclusions may be deduced from the treatment of supplements by individual European countries as well. For instance, Germany treats any supplements containing herbs as prescription drugs, a profound variance from the libertarian model inherent in DSHEA. ${ }^{376}$

On the other hand, might the relaxed regulatory treatment of dietary supplements in the United States also reflect sufficient private deterrents? Intriguingly, despite the infamy of several supplements, the vast majority appear remarkably benign, notwithstanding their uncertain effectiveness and oftenmislabeled ingredient content. This may suggest that forces within the dietary supplement industry, such as voluntary certification programs or industry watchdogs, augment tepid governmental regulation of supplements.

Indeed, since passage of DSHEA, several private organizations have created voluntary certification programs to monitor industry behavior. For instance, the United States Pharmacopoeial Convention sets standards for some nutrients, including quality control, good manufacturing practices, and assurances that

370 Communication from the Commission on the Precautionary Principle, Commission of the European Communities, COM (2000), Feb. 2, 2000, at 7; see also George E.C. York, Global Foods, Local Tastes \& Biotechnology: The New Legal Architecture of International Agriculture Trade, 7 COLUM. J. EUR. L. 423, 443-46 (2001) (explaining usage of the precautionary principle in Europe).

371 Wilson Huhn, Three Legal Frameworks for Regulating Genetic Technology, 19 J. CONTEMP. HEALTH L. \& POL'Y 1, 33 (2002).

${ }_{372}$ See, e.g., U.N. Conf. on Env't and Dev., Rio Declaration on Env't and Dev., Principle 15, U.N. Doc. A/Conf.151/5 (1992), reprinted in 31 I.L.M. 874 (1992) (finding that lack of absolute scientific certainty should not impair "cost effective measures" when those measures do not appear harmful); see also Sarah Lively, The ABCs and NTBs of GMOs: The Great European Union-United States Trade Debate-Do European Restrictions on the Trade of Genetically Modified Organisms Violate International Trade Law?, 23 N.W. J. INT'L L. \& BUS. 239, 246-248 (explaining limits of the Precautionary Principle in the EU).

${ }_{373}$ Volkert Dethlefsen et al., The Precautionary Principle: Towards Anticipatory Environmental Management, in CleAN Production StRategies 41, 41-62 (Tim Jackson ed., 1993).

374 Paula Fitzgerald Bone \& Karen Russo France, International Harmonization of Food and Nutrition Regulation: The Good and the Bad, 22 J. PUBLIC POL'Y \& MKTG. 102 (2003).

${ }_{375}$ See generally Geraint G. Howells \& Mark Mildred, Is European Products Liability More Protective than the Restatement (Third) of Torts: Products Liability?, 65 TENN. L. REV. 985 (1998); see also Douglas A. Kysar, The Expectations of Consumers, 103 COLUM. L. REV. 1700 (2003) (explaining the role of the consumer expectations test in American jurisprudence).

376 Jane E. Allen, No Minor Mix-up, L.A. TIMES, Jan. 10, 2000, at 1. 
products match label claims and contain digestible ingredients. ${ }^{377}$ Participating companies which demonstrate integrity, potency, and purity within their products may place a "USP-Verified" seal on their products' labels. ${ }^{378}$ Similarly, the National Sanitation Foundation, which includes representatives from academia, government agencies, and manufacturers, not only tests the accuracy of supplement claims, but also periodically audits participating manufacturers to insure continued quality control. Like the "USP-Verified" seal, compliant manufacturers earn NSFcertificates, which they may use as marketing devices. ${ }^{379}$ By rewarding compliant behavior, private monitoring incentivizes the production of quality products. Moreover, seals communicate meaningful information to consumers for selecting dietary supplements: those containing a label seal have been recognized as legitimate and safe by a third party.

Perhaps more effective than voluntary certification programs are industry watchdogs, since they may evaluate any product on the market. To illustrate, consider ConsumerLab.com, which regularly tests dietary supplements containing herbs. The company has revealed that 40 percent of herbal supplements do not contain the active ingredients listed, while many others contain less or more of a particular ingredient listed or simply contain the wrong herb. ${ }^{380}$ Indeed, research conducted for ConsumerLab.com and similar watchdogs reveals wide variability in supplement ingredients, with active ingredients often proving inconstant, unpredictable, or simply unknown. ${ }^{381}$ This is especially troublesome for children, who, by virtue of their smaller size and diminished capacity for detoxifying chemicals, are more susceptible to the effects of dosage variations. ${ }^{382}$ Thus, industry watchdogs can illuminate vital deficiencies among the entire spectrum of dietary supplements, thereby enhancing consumer choice.

Lastly, market inducements for self-policing among dietary supplement manufacturers affect industry practices. For instance, negative publicity of any dietary supplement product may adversely affect sales of other supplements. ${ }^{383}$ Along those lines, studies suggest that recent fallout from the ephedra controversy has slowed the growth of the supplement industry and caused consumers to become warier of all supplement products. ${ }^{384}$ A more skeptical societal view of dietary supplements might also increase the prospect of civil litigation for a wider scope of industry actors. ${ }^{385}$ For these reasons, supplement manufacturers have initiated collaborative self-policing efforts. To illustrate, consider that industry suasion has

377 See generally U.S. Pharmacopoeia, http://www.usp.org/ (last visited Jan. 10, 2005).

378 U.S. Pharmacopocial Convention, Dietary Supplements, available at http://www.usp.org/dietarySupplements/ (last visited Jan. 8, 2005).

379 Judy Packer-Tursman, Ceriified, to a Point, WASH. POST, Nov. 19, 2002, at F01 (citing industry research finding that when a consumer is given the choice between two products, all other things being equal, the consumer will select the product that has a credible third-party certification).

$380 \quad$ See Allen, supra note 98.

381 See Woolf, supra note 54.

$382 \quad I d$.

383 See Betsy Streisand, The Guru of Product Potential, N.Y. TIMES, Aug. 31, 2003, § 3, at 1 (citing comments by Patrick D. Rea of the Nutrition Business Journal concerning the impact of negative publicity on the entire dietary supplement market).

${ }_{384}$ Id. (citing study by Nutrition Business Journal which found slowing industry growth and citing comments by Patrick D. Rea of the Nutrition Business Journal concerning the impact of negative publicity).

${ }_{385}$ This phenomenon appeared in the tobacco litigations, as the industry's reputation plummeted with a flurry of lawsuits, which only beget another series of litigations. See Lynn Mather, Theorizing about Trial Courts: Lawyers, Policymaking, and Tobacco Litigation, 23 LAW \& Soc. INQUIRY 897, 935 (1998). 
increasingly convinced individual supplement manufacturers to standardize their products, thus guaranteeing ingredient consistency among every capsule. ${ }^{386}$ Similarly, to resist regulatory encroachment by the FDA, larger supplement manufacturers have lobbied smaller ones to provide explicit warning labels. ${ }^{387}$ Although often informal and haphazard, self-policing among dietary supplement manufacturers might impose a higher "cost" for market manipulation whenever deviant actors are stigmatized, thus diminishing the frequency of such behavior. ${ }^{388}$

Though private enforcement mechanisms may partly fill the vacuum for dietary supplement regulation, they have historically proven less effective than government regulation. Indeed, they are often implemented on an ad hoc basis, with only some dietary supplement manufacturers agreeing to cooperate. This is especially apparent with voluntary certification programs, which attract only a minority of recent entrants into the dietary supplement industry. ${ }^{389}$ Moreover, the very concept of voluntary participation begs an important corollary: those manufacturers which agree to external review of their products appear qualitatively different than those which do not, thus evincing a predictive self-selection bias among participants.

Label certification might also mislead consumers into false deductions. For instance, the USP-verified seal indicates that a product contains its stated ingredients and that proper manufacturing practices were employed; a consumer, however, may mistakenly believe that the seal also endorses the product's claims (e.g., "boosting energy" or "enhancing memory"). ${ }^{390}$ As a result, a consumer may derive false confidence in a product and may purchase that product on false pretenses. ${ }^{391}$ More troubling, manufacturers may manipulate false deductions, particularly if conflicting standards give rise to consumer confusion. ${ }^{392}$

For both methodological and structural reasons, industry watchdogs are similarly restrained in their capacity to enhance consumer choice. First, they tend to test mere samples of dietary supplement products, a procedure which fails to contemplate frequent ingredient distortions within an individual product line. ${ }^{393}$ Moreover, though industry watchdogs overcome self-selection bias by independently selecting products for analysis, aversion to potential lawsuits deters them from revealing the names of "flunking" products. ${ }^{394}$ Consequently, they tend to publicize

386 See Linda Saslow, Nassau Restricts Herbal Aids with Stimulant, N.Y. TIMES, Aug. 18, 1996, § 13LI, at 1 (citing comments by Gerard McIntee, director of marketing for Nature's Plus, a manufacturer of vitamins and herbs).

$1 \mathrm{C}$.

${ }_{387}$ See Bruce Japsen, FDA Could Supplement Vitamin Regulation, CHI. TRIB., Sept. 6, 1998, at

388 This phenomenon has been evidenced among those industries where actors exploit cheap, foreign labor. See William B. Sorbella, Less Developed Country as Start-up Corporation: Adopting the Venture Capital Model for Development in Light of Global Capital Market Realities, 31 L. \& POL'Y INT'L BUS. 517, 542 (2000).

${ }_{389}$ See Allen, supra note 98 , (citing comments by Annette Dickinson, the president of the Council for Responsible Nutrition).

390 See Packer-Tursman, supra note 379 (citing comments by David Schardt, senior nutritionist at the Center for Science in the Public Interest).

391 Similar false deductions often arise with "green" symbols indicating that a product is somehow environmentally-friendly. Many times, those products either offer no meaningful environmental benefit or are based deceptively on half-truths. See generally Roger D. Wayne, The Emperor's New Eco-Logos?: A Critical Review of the Scientific Environmental Report Card and the Green Seal Certification Mark Programs, 14 VA. ENVTL. L.J. 51 (1994).

${ }_{392}$ See Douglas A. Kysar, Preferences for Processes: the Process/Product Distinction and the Regulation of Consumer Choice Preferences, 118 HARV. L. REV. 525, 626-27 (2004).

393 See Uli Schmetzer, Australia Recalls Diet Supplements, CHI. TRIB., May 2, 2003, at C4.

394 See Packer-Tursman, supra note 379. 
only those products which pass sufficiency standards-meaning that products presenting the greatest danger and inefficacy remain unknown to consumers. Of greater concern, watchdogs may afford preferential treatment to supplier partners and fail to disclose this influence when posting results. For instance, in February 2005, the Council for Responsible Nutrition urged the FTC to investigate whether ConsumerLab.com intimidates supplement manufacturers into paying for its services to avoid less favorable results.

Likewise troubling, self-policing among dietary supplement manufacturers often proves inadequate and unpredictable. This is particularly apparent given the wide variances among industry participants, with manufacturers possessing disparate incentives depending on size and diversity of product line. ${ }^{395}$ Accordingly, while a number of large, established dietary supplement manufacturers produce multiple product types, including pharmaceuticals and over-the-counter medicines, smaller operations have limited resources for testing and greater desire for "the quick buck." 396 Given such market heterogeneity, negotiating common guidelines tends to prove difficult, thus diminishing the potential for consumer elucidation. ${ }^{397}$

\section{MAXIMIZING CONSUMER CHOICE \& AUTONOMY FOR DIETARY SUPPLEMENT CONSUMPTION}

As explored in this Article, existing legal frameworks encourage the distribution of indeterminable dietary supplements into the same stream of commerce as safe and effective dietary supplements, as well as FDA-approved drugs and food products. Peculiarly, despite incalculable enhancements in testing and information-sharing technologies, lawmakers treat dietary supplements much like they were treated by the Pure Food and Drugs Act of $1906^{398}$, which likewise placed the burden on the federal government to discover dangerous product ingredients, and which likewise offered scant incentive for voluntary disclosure of adverse health-related phenomena. ${ }^{399}$ This is of particular concern, since consumers significantly undervalue the ease with which dietary supplements may enter the market and the extent of damage such supplements must cause before governmental actors may legally intervene. Moreover, because of cognitive biases, certain population groups, including the young and the economically-disadvantaged, excessively underestimate the relevant risks of dietary supplement consumption. Only further disrupting consumer perception, market participants often manipulate these biases through misleading advertising and erroneous product labeling. Although private enforcement mechanisms offer marginal deterrence to deviant market behavior, they tend to lack the thrust and consistency of effective government regulation found in other realms of food and drug law.

395 See Shari Roan, Recall of 2 Products Points Up Risk of Using Supplements, L.A. TIMES, Feb. 18, 2002, at S3.

${ }_{396}$ For example, Chattem, the Chattanooga-based health and beauty aids company, produces Ban deodorant, Icy Hot topical pain reliever, Selsun Blue dandruff shampoo, and the Dexatrim nutrient and energy bar. See generally http://www.chattem.com/ (last visited Jan. 10, 2005); see also Japsen, supra note, 387 (explaining difficulties of negotiations between larger supplement manufacturers and those with short-term desire for significant revenue).

397 See Japsen, supra note 387.
Pub. L. No. 59-384, ch. $3915, \S 2,34$ Stat. 768 (1906) (superseded by the FD\&C Act in 1938).

Id. 
Nevertheless, dietary supplements comprise a highly-valued and occasionally singular product line for many consumers. Indeed, certain consumers possess abnormally high nutritional needs, which dietary supplements can most effectively address. ${ }^{400}$ Likewise, consumers place significant value in the capacity to choose health-related products, and some simply prefer "natural" substitutes to those products supplied by the pharmaceutical drug industry, which is sometimes criticized for price gouging. ${ }^{401}$ Even when dietary supplements prove clinically inefficacious, consumers sometimes identify immeasurable, but appreciable, holistic, psychiatric, and even spiritual therapeutic benefits. ${ }^{402}$ More abstractly, consumer choice may be considered a positive value, and consumer capacity to select the bundle of risks and benefits associated with supplements cannot be dismissed with paternalistic gloves. ${ }^{403}$

Any optimal regulatory system for dietary supplements must thus advance two essential, if competing, goals: 1) protect those most vulnerable from misleading health claims and unanticipated contents; and 2) enable an informed consumer class to purchase appreciably-beneficial products at predictable and affordable prices. Admittedly, crafting such a framework appears uniquely challenging in light of obvious political constraints. ${ }^{404}$ However, this Article will propose two fundamental alterations that can ameliorate consumer interaction with dietary supplements and benefit both market participants and consumers. Indeed, in linking consumer and industry incentives, meaningful measures may be promulgated to enhance the interests of all affected parties.

\section{A. LABeling Requirements \& CONSUMER CHOICE}

More carefully-contemplated labeling requirements for dietary supplements would enhance consumer risk-assessment and reward reputable supplement manufacturers. Under current requirements, supplement manufacturers must utilize the "Supplement Facts" panel, which divulges information on essential nutrients and other dietary ingredients upon which a nutritional claim is based. ${ }^{405}$ Though the Supplement Facts panel facilitates comparison of supplement products, it omits consequential information for consumers, including potential interactions with pharmaceutical drugs and other supplements. For instance, unbeknownst to many users, the herbal supplement St. John's Wort has been linked to organ rejection in patients taking the drug ciclosporin. ${ }^{406}$ Similarly, the Supplement Facts format fails

$400 \quad$ See Shalala, 504 F.2d at 789.

See Rhonda Kay McPherson, Pharmaceuticals: Politics, Policy \& Availability, 8 GEO. PuBliC POL'Y Rev. 25, 31 (2003); see also Abner J. Mikva, Deregulating Through the Back Door: The Hard Way to Fight a Revolution, 57 U. CHI. L. REV. 521, 523 (describing early legislative efforts to control pharmaceutical price gouging).

402 See supra Part II.D.

403 See generally Richard H. Thaler, TOWARd a Positive THEORY of CONSUMER Choice, in ChOlCES, VAlues, AND Frames 269 (Daniel Kahneman \& Amos Tversky eds., 2000).

404 Indeed, even Dr. Kessler has noted that there are "certain problems you are not going to solve" and dietary supplements are "one of them." See Gilhooley, supra note 168 (citing Marian Burros, F.D.A. Commissioner Is Resigning After 6 Stormy Years in Office, N.Y. TIMEs, Nov. 26, 1996, at Al).

405 See supra Part III.F.

406 See T.H. Breidenbach et al., Drug Interaction of St. John's Wort with Ciclosporin, 355 LANCET 1912 (2000). Also consider that herbal products are often sold as mixtures of 10 or more different plants, vitamins, and minerals, and that such "stacking" of herbs increases the risk of toxicity from any one of them or from interactions with each other. See Woolf, supra note 54. 
to warn of over-usage. Indeed, long-term excessive use of vitamins and minerals might cause diarrhea, liver abnormalities, and other health ailments. ${ }^{407}$

These forms of information would considerably improve consumer insight, particularly since package labeling has been found to communicate consumer choice. Specifically, when nutritional disclosures are prominently and contextually displayed on labels, they may significantly assist consumers in discerning misleading suggestions from nutrient content claims, ${ }^{408}$ principally linkages between nutrient consumption and disease reduction (e.g., "low-fat diet leads reduces the chances of cancer"). ${ }^{409}$ Labeling requirements would also counter consumer tendency to lack sufficient grasp of dietary information, particularly when assessing desired consumption levels. ${ }^{410}$ It is this latter lesson from the European-based Precautionary Principle that appears particularly beneficial for American consumers.

For similar reasons, the Supplement Facts panel should be revised to express age and gender-based "daily values" of each provided nutrient. Curiously, the current Supplement Facts format assumes that an 18 year-old man and an 81 yearold woman share the very same dietary needs. Indeed, consider that the daily value for calcium is 1,000 milligrams, a figure based on the dietary needs for adults aged 31 to $50 .^{411}$ Older adults, particularly older women, however, are expected to digest significantly higher daily doses of calcium. ${ }^{412}$ Similar defects are associated with iron, vitamin $\mathrm{B}$, and selenium daily values. ${ }^{413}$ Other daily values dramatically overstate dietary needs. For instance, the daily values for zinc and phosphorous are based primarily on the needs of growing teenage males and overstate the needs for over 90 percent of the population. ${ }^{414}$ Consequently, dietary supplements may mislead consumers into unappreciated purchases. This is of particular concern for older Americans, whose cognitive biases increase the probability of optimistic purchasing and who data suggest often view supplements as substitutes for drugs and medicine. ${ }^{415}$

Although no label can communicate dietary information tailored for individual consumption, perhaps a better framework would entail ranges based on age and gender. The calcium example above appears to corroborate this idea: a range for recommended intake based on age and gender would prove illuminating for many consumers. Presented more effectively, nutritional labeling can diminish the effect of misleading product advertising, a common defect of dietary supplement

407 See Andrew Martin, Panel Urges FDA Alter List of Daily Nutrients, CHI. TRIB., Dec. 12, 2003, at $\mathrm{Cl}$ (citing research by Dr. Irwin Rosenberg, dean of the Gerald J. and Dorothy R. Freidman School of Nutrition Science and Policy at Tufts University).

408 See J. Craig Andrews et al., Consumer Generalization of Nutrient Content Claims in Advertising, 62 J. MARKETING 62 (1998).

409 Id. at 63.

410 See Alan S. Levy et al., Consumer Impacts of Health Claims: An Experimental Study, Center for Food and Applied Nutrition, FDA, Jan. 10, 1997, available at http://vm.cfsan.fda.gov/dms/hclm-toc.html; see also Marilyn Chase, Lost in Fat City: Studies Stir Confusion Over Butter and Oils, WALL STREET J., July 10, 1995, at B1.

411 See Note, What you Need to Know about Calcium, 6 HARV. HeAlTh LeTTER 1 (Apr. 2003).

412 Id.; see also Squires, supra note 315 (noting that the National Institutes of Health recommends 1,500 milligrams of calcium per day for older women).

${ }_{413}$ See Erin O'Donnell, How to Buy the Best Vitamin, 2 NAT'L HEALTH 76 (2003) (citing research of Dr. Jeffrey Blumberg of Tufts University, who notes that seniors and women often benefit with higher doses of nutrients than recommended by daily values).

414 See Martin, supra note 407 (citing remarks by Dr. Irwin Rosenberg, dean of the Gerald J. and Dorothy R. Freidman School of Nutrition Science and Policy at Tufts University).

415 See supra Part III.C and accompanying notes. 
advertising. ${ }^{416}$ This would seem especially true if better instructions existed on how to read a supplement facts label. ${ }^{417}$ Moreover, considering the relatively low-cost of food and drug labeling, nuanced labeling requirements would refrain from burdening supplement companies with exacerbated production costs.

On the other hand, product labels contain limited surface areas, and implementation of the aforementioned ideas would undoubtedly absorb greater surface area than is currently affected by FDA regulation. Also, and not surprisingly, when food and drug manufacturers encounter proposals that would diminish the available label surface area for promotional language and design, they often express fierce resistance. 418 Specifically, they contend that "simplified" required disclosures communicate the most salient information. ${ }^{419}$ This position is not without merit, as "information overload," whereby labels exhibit too many warnings or data, can confuse or frustrate consumers, leading them to misinterpret or ignore crucial information. ${ }^{420}$ In other words, product labels may tell more by stating less, and thus labeling regulation must judiciously account for available surface area.

Nevertheless, utilizing a product label to illuminate potential substance interactions, dangers of over-usage, and age and gender-based daily values appears not only desirable, but also compatible with supplement label surface areas. Indeed, an unscientific survey of twenty distinct dietary supplement products reveals that marketing and promotional information (i.e., text, graphics, artwork, claims, and unused background) comprises approximately 60 percent to 80 percent of available labeling space. ${ }^{421}$ Thus, at least suggestively, dietary supplement labels appear hospitable to additional disclosure of meaningful nutritional information. For instance, broadly defined, yet instructive age and gender based daily ranges could be employed, such as "males between the ages of 24 and 38." These ranges could be displayed in chart format, akin to the existing supplement facts format and thus immediately familiar to consumers. Moreover, if disclosure of certain information would risk information overload, a package insert could supplement labeling information. This would seem perhaps most appropriate for potential interactions

416 See Andrews et al., supra note 408, at 72.

417 See Marian Burros, Read Any Good Nutrition Labels Lately?, N.Y. TIMES, Dec. 1, 2004, at F1 (noting that while many Americans find food labels useful, many also struggle with utilizing all aspects of it; Professor Burros proposes that Americans receive better education on how to observe the facts panel).

418 See, e.g., Prepared Testimony of Al Clausi and the National Food Processors' Association before the Senate Labor and Human Resources Committee, FEDERAL NEwS SERV., Apr. 11, 1997, available at LEXIS News Database (concluding that proposed FDA changes to food labels would "unnecessarily take up label space").

419 See, e.g., FDA Folic Acid Health Claim Misses Mark, CRN Says, PR NEwSWIRE, Oct. 21, 1993, available at LEXIS Newswire (citing remarks by Paul Bolar, director of regulatory affairs for Pharmavite Corporation and chairman of Council for Responsible Nutrition's quality assurance committee).

${ }^{420}$ See Jayachandran N. Variyam, New Health Information is Reshaping Food Choices, 1 FOOD REV. 13 (2002). This defect of product labeling is identified with pharmaceutical drug labels, which often contain myriad disclosures in tiny font type. See generally Mark Geistfeld, Inadequate Product Warnings and Causation, 30 U. MICH. J.L. REF. 309 (1997); see also Roberta Romano, A Comment on Information Overload, Cognitive Illusions, and Their Implications for Public Policy, 59 S. CAL. L. REv. 313 (1986) (providing detailed analysis of information overload).

${ }_{421}$ I measured the surface areas from labels of the following products: Advanced Whey Protein; Centrum Performance; BCAA Plus; Universal Nutrition Amino 1900; Carb Intercept; Centrum; Cher-Amino Protein; Cytovol; Glutamine Fuel; Glutamine Powder; Lean Max Matrix Protein; Leptropin-Anorex; Max-Amino; Mood Factors; Muscle Mix; Perfect L-Glutamine; Power Bar Harvest; Super Amino; Tazo Green Ginger Green Tea; and Vogi Herbal Tea. 
with pharmaceutical drugs and other supplements, where the product label could alert the consumer of the most salient interaction and an insert could provide supplemental data. ${ }^{422}$

Perhaps cognizant of these phenomena, recent court decisions have clarified the need for nuanced health claims on supplement labels when the health claims are based on new scientific data. ${ }^{423}$ Namely, in Pearson, the court determined that whenever label disclaimers can eliminate potential consumer confusion associated with related health claims, such disclaimers-and related claims-should be allowed. ${ }^{424}$ Accordingly, in 2003, the FDA published interim guidance procedures ("Interim Guidance Procedures"), which promote a rating system to characterize the strength of scientific evidence that supports purported nutrient-disease relationships on labels. ${ }^{425}$ Most significantly, the Interim Guidance Procedures established "qualified health claims," which are based on presumptively promising, yet inconclusive scientific data, and which require FDA approval. It is thought that this more nuanced approach to supplement labeling enables consumers to obtain more timely access to critical information concerning nutrition and disease riskreduction. ${ }^{426}$ To date, the agency has approved three qualified health claims, one for chopped walnuts, ${ }^{427}$ one for omega-3 fatty acids, ${ }^{428}$ and one for monounsaturated fat from olive oil. ${ }^{429}$ The long-term implications of qualified health claims are uncertain, though if granted judiciously, they appear to facilitate the disclosure of timely and FDA-approved label information and more carefully distinguish health claims from structure/function claims. ${ }^{430}$

422 This arrangement could approximate that for pharmaceutical drugs. Indeed, for particular pharmaceutical drugs, the FDA requires that package inserts containing product information be provided and that such inserts inform product users of the risks and benefits associated with usage. See Mae Joanne Rosok, Direct-to-Consumer Advertising of Prescription Drugs: After a Decade of Speculation, Courts Consider Another Exception to the Learned Intermediary Rule, 24 SEATTLE UNIV. L. REV. 629, 638 (2000) (citing See Patient Package Inserts for Oral Contraceptives, 21 C.F.R. $\S$ 310.501 (2000); Patient Package Inserts for Estrogens, 21 C.F.R. $\$ 310.515$ (2000).

${ }^{423}$ See FDA's Implementation of "Qualified Health Claims": Questions and Answers, Apr. 2004, available at http://www.cfsan.fda.gov/ dms/labqheqa.html.

${ }_{424} 164$ F.3d 650 (D.C. Cir. 1999) (basing decision on the First Amendment and administrative record compiled in the challenged rulemakings).

425 See FDA, Guidance for Industry and FDA: Interim Evidence-Based Ranking System for Scientific Data \& Guidance for Industry and FDA: Interim Procedures for Health Claims in the labeling of Human Dietary Supplements (July 10, 2003), available at http://vm.cfsan.fda.gov/ dms/hclmgui3.html.

${ }_{426}$ See Acting FDA Commission Speaks at Council for Responsible Nutrition Annual Conference, STATES NEWS SERVICE, Oct. 25, 2004, available at LEXIS News Wire.

${ }_{427}$ Vendors of chopped walnuts may claim "supportive but not conclusive research shows that eating $1.5 \mathrm{oz}$. [a little more than a handful] of walnuts per day as part of a low saturated fat and low cholesterol diet, and not resulting in increased caloric intake, may reduce the risk of coronary heart disease." See Sally Squires, Omega-3 Foods Can Put Benefits on Label, FDA Says, WASH. POST, Sept. 9, 2004, at A04.

${ }_{428}$ Products containing omega- 3 fatty acids may state "Supportive but not conclusive research shows that consumption of EPA and DHA omega-3 fatty acids may reduce the risk of coronary heart disease." Id.

${ }^{429}$ See FDA, FDA Allows Qualified Health Claim to Decrease Risk of Coronary Heart Disease, (Nov. 1, 2004), available at http:/www.fda.gov/bbs/topics/news/2004/NEW01 129.html (noting that "There is limited but not conclusive evidence that suggests that consumers may reduce their risk of CHD if they consume monounsaturated fat from olive oil and olive oil-containing foods in place of foods high in saturated fat, while at the same time not increasing the total number of calories consumed daily).

430 Others are more skeptical, however. In Center for Science in the Public Interest v. FDA, 2004 U.S. Dist. LEXIS 20781 (U.S.D.C. Sept. 17, 2004), a consumer group sued the FDA, alleging that the Interim Guidance Procedures, in failing to comply with the procedural requirements and 
Enhanced enforcement of existing statutes can also promote communication of label information to consumers. Indeed, many supplements list erroneous ingredients, inaccurate estimations of certain contents, and false or misleading claims. With more scrutinized labels, however, incentives for market manipulation and production of dangerous products would diminish. Recent activity suggests the FDA is increasingly engaged in such scrutiny. Notably, in United States v. Lane Labs-USA, Inc., ${ }^{431}$ the FDA succeeded in asserting that a company had falsely labeled dietary supplement products as treatments for cancer and HIV. ${ }^{432}$ The significant media attention to Lane Labs-USA, coupled with a severe sanction, ${ }^{433}$ likely deters those manufacturers contemplating label deceit.

Though less dramatic, the FDA has more regularly dispatched warning letters to companies making false label claims about weight loss, particularly in the wake of ephedra. ${ }^{434}$ Equally significant are the FDA's proposed revised Good Manufacturing Practices ("GMPs") for dietary supplement companies. GMPs allow greater inquiry into production process, raw materials, testing, and record keeping in order to improve product quality and increase the likelihood of consistency between labels and ingredients. ${ }^{435}$ They also offer additional means by which the FDA can pursue legal action against unscrupulous companies. ${ }^{436}$

Increased integration between the FDA and FTC in regulating false or misleading dietary supplement labeling would further discourage inaccurate supplement labels. Promisingly, in December 2002, the two agencies formed a joint enforcement task force, and they have since worked closely in challenging false claims of supplement effectiveness for treating a range of diseases. ${ }^{437}$ Together, they have since brought more than 40 actions targeting fraudulently marketed

substantive standards of the NLEA, allows health claims without the requisite scientific support. Although the case was dismissed in September 2004 for lack of standing, the manner and willingness with which the FDA approves qualified health claims should be monitored closely to ensure sufficient consumer protection. Similar concerns have been raised of the lack of specificity of qualified health claims. See, e.g., Squires, supra note 427 (quoting Bruce Silverglade of the Center for Science in the Public Interest).

431 324 F. Supp. 2d 582 (D.N.J. 2004).

432 Because of such specific health claims, the court deemed the product's marketing as consistent with drug marketing. Thus, the product was considered an unapproved new drug with a misbranded label. Id. at 582-84.

${ }^{433}$ The sanction included: all inventory of these products be destroyed under FDA supervision and Lane Labs make restitution on all sales of these products since 1999. Id.

${ }^{434}$ See FDA Press Release, Acting FDA Commissioner Dr. Lester M. Crawford Outlines Science-Based Plan for Dietary Supplement Enforcement, Apr. 19, 2004, available at LEXIS News Wire.

435 See Joseph A. Levitt, FDA's Plate Remains Full, LEGAL TIMEs, Mar. 1, 2004, at 25. Dietary supplement GMPs were originally enacted by DSHEA. Specifically, DSHEA amended the FDC Act and added the dietary supplement CGMP, which deems a product "adulterated," if "it is a dietary supplement and it has been prepared, packed, or held under conditions that do not meet current good manufacturing practice regulations, including regulations requiring, when necessary, expiration date labeling, issued by the Secretary under subparagraph (2). 21 U.S.C. $\S 342(\mathrm{~g})(1)$. Subparagraph (2) of $\S 342(\mathrm{~g})$ provides that, "the Secretary may by regulation prescribe good manufacturing practices for dietary supplements. Such regulations shall be modeled after current good manufacturing practice regulations for food and may not impose standards for which there is no current and generally available analytical methodology." 21 U.S.C. $\S 342(\mathrm{~g})(2)$.

${ }_{436}$ See, e.g., Nutritional Health Alliance v. FDA, 318 F.3d 92 (6th Cir. 2003).

437 See FDA, Acting FDA Commissioner Dr. Lester M. Crawford Outlines Science-Based Plan for Dietary Supplement Enforcement, (Apr. 19, 2004), available at http:/www.fda.gov/bbs/topics/news/2004/NEW01055.html. 
supplements and other health products. ${ }^{438}$ Most recently, in November 2004, the FTC charged three related dietary supplement companies with deceiving consumers through deceptive advertising for their supplement products, which falsely claim to combat weight-gain and erectile dysfunction. ${ }^{439}$ The FTC has pledged to work closely with the FDA to combat deceptive claims for dietary supplements. ${ }^{40}$

With more accurate, complete, and verifiable dietary information, consumers can better determine the relative utility of one product over another and thus more correctly project outcomes that result from the decision to consume particular dietary supplements. ${ }^{41}$ Such information would also diminish the effect of cognitive tendencies to presume non-existent content benefits, as well as the related effects of misleading advertising and distorted label claims. Equally important, dietary supplement manufacturers would appreciate corresponding gain through heightened labeling standards: consumer confidence in industry tends to rise when they observe familiarity and confidence in standardized techniques. ${ }^{442}$ Although such standards may impair the business operations of less reputable manufacturers, they would reward more reputable manufacturers by distinguishing their products as qualitatively superior.

\section{B. Product Registration, Adverse Reaction Reporting \& Consumer CHOICE}

Dietary supplement manufacturers should also be obligated to register ingredient contents with the FDA and to report adverse reactions to all products. These two concepts are related in practice and in form and impact the veracity of labeling claims. Under the current regulatory framework, manufacturers fail to voluntarily reveal over 99 percent of adverse reactions reported by consumers, and the FDA typically learns of the relatively few reported adverse-reactions too late to prevent further harm. ${ }^{43}$ This problem is compounded by the absence of registration

${ }^{438}$ See Prepared Statement of the Federal Trade Commission, Before the Comm. on Energy and Commerce, Subcomm. on Oversight and Investigations, 108th Cong. (June 16, 2004), available at http://www.ftc.gov/os/2004/06/040616dietarysupptestimony.pdf.

439 See Federal Trade Commission v. National Urilogical Group et al., Civil No. 1:04-GV3294, (D.G.A. Nov. 30, 2004), available at http:/www.ftc.gov/os/caselist/0223165/041130comp0223165.pdf. In August 2004, the FDA also negotiated a $\$ 1$ million settlement with two dietary supplement marketers who had falsely advertised that certain dietary supplements caused substantial weight loss without diet or exercise. See FTC Press Release, Two Maine Dietary Supplement Marketers Pay Nearly \$1 Million to Settle FTC Deceptive Advertising Complaints (Aug. 27, 2004), at http://www.ftc.gov/opa/2004/08/pvt.htm.

${ }_{440}$ See FTC Press Release, FTC Charges Marketers with Making Deceptive Efficacy and Safety Claims about Ephedra and Yohimbine Dietary Supplements (Nov. 30, 2004), at http://www.ftc.gov/opa/2004/11/nationalurological.htm.

${ }_{441}$ See generally James R. Bettman, An Information Processing Theory of Consumer CHOlCE 173-228 (Addison-Wesley Publishing Co. 1979) (explaining Theory of Consumer Choice); see also McCann, supra note 225, at 1177 (explaining consumer choice in the context of food consumption choices).

${ }_{442}$ See, e.g., Lauren Fisher Kellner, Trade Dress Protection for Computer User Interface "Look and Fee", 61 U. CHI. L. REV. 1011, 1023 (1994) (describing the increase of consumer confidence in microcomputer markets with predictable and standardized labeling mechanisms); Thomas T. Reith III, Consumer Confidence: The Key to Successful E-Commerce in the Global Marketplace, 24 SUFFOLK TRANSNAT'L L. REV. 467, 484 (2001) (noting that the EU's Organisation For Economic Cooperation and Development finds that a combination of industry standards and governmental legislation may lead to enhanced consumer confidence).

${ }^{443}$ See supra Part IV.B. 
for dietary supplement products: The FDA cannot determine the ingredients of nearly one third of the supplements for which adverse reactions are reported. ${ }^{444}$

Particularly for those vexatious ingredients that have been banned in other countries, such as the herb aristolochia or the plant extract germander, ${ }^{445}$ registration would enable the FDA to more efficiently respond to any adverse reactions or, should the FDA likewise ban those ingredients, to expedite removal of affected products. Moreover, though it may appear unnecessary and perhaps burdensome to require that supplement manufacturers register seemingly innocuous ingredients, such as vitamin $\mathrm{C}$ or zinc, emerging scientific data can always cast doubt on prior conclusions. Indeed, recent studies suggest that certain levels of Vitamin C consumption might even prove harmful. ${ }^{46}$ Thus, under an optimal regulatory framework, all supplement ingredients should be subject to registration. This position seems particularly sensible given that ingredient registration would not impose material costs upon manufacturers-assuming, of course, the manufacturers are aware of their own products' ingredients.

Likewise significant, ingredient registration would enhance lines of communication between the FDA and supplement manufacturers, as industry and governmental actors would share product information, thus enhancing the reliability of adverse event reporting. Such enhanced communication would also bolster recent proposals that emphasize greater cooperation between FDA administrators and industry actors ${ }^{447}$ and would help repair historically-strained relations between those administrators and supplement manufacturers. ${ }^{448}$ Furthermore, ingredient registration would follow a trend towards expanded registration of supplement manufacturers. Indeed, the Bioterrorism Act of 2002 requires supplement manufacturers to register location of their facilities, ${ }^{449}$ thus enabling the FDA to more efficiently isolate problematic ingredients and work with manufacturers on resulting product enhancement. Similarly meaningful, manufacturing registration allows the FDA to determine which facilities to inspect, thereby reducing unnecessary disruption of reputable manufacturers.

Administration of adverse event reporting likewise warrants attention. Although the FDA has recently introduced a more sophisticated adverse event reporting system (CAERS), ${ }^{450}$ as well as pledged more thorough review of

444 See Food Safety: Improvements Needed in Overseeing the Safety of Dietary Supplements and "Functional Foods", Gen. Acct. Off. Rep. No. RCED-00-156, at 12 (July 11, 2000), available at http://www.gao.gov/archive/2000/rc00156.pdf.

445 Aristolochia has been linked to kidney failure and cancer and has been banned in 10 countries. Germander has been linked to liver damage and has been banned in Germany and France. See Twelve Supplements You Should Avoid, CONSUMER REPORTS, May 2004, available at http://www.consumerreports.org (last visited, Feb. 15, 2005).

446 See Seon Hwa Lee, et al., Vitamin C-Induced Decomposition of Lipid Hydroperoxides to Endogenous Genotoxins, 292 SCIENCE 2083 (2001).

${ }_{447}$ See Chryssa V. Deliganis, Death by Apple Juice: The Problem of Foodborne Illness, the Regulatory Response, and Further Suggestions for Reform, 53 FOOD DRUG L.J. 681, 725 (1998).

448 See supra Part III.

44921 U.S.C. $\S 350 \mathrm{~d}(\mathrm{a})(1)$ (Supp. 2002); see also Hutt, supra note 283, at 17 ("All of the provisions in the Bioterrorism Act apply to dietary supplements and dietary ingredients as well as to conventional foods").

${ }_{450}$ In 2003, the FDA's Center for Food Safety and Applied Nutrition (CFSAN) established the Center's Adverse Event Reporting System (CAERS) to monitor adverse event reports on CFSANregulated products, including dietary supplements. CAERS is a computerized system that records voluntarily received reports and separates them into product problems and adverse events. This system unifies CFSAN's adverse event reporting through one common portal. See Statement of Robert E. Bracket, supra note 272. 
individual dietary supplements, ${ }^{451}$ placing the burden on the agency appears undesirable when manufacturers often enjoy optimal information at the earliest date. This is especially true of adverse effects that are unknown at the time of marketing, since customer complaints to the company typically emerge well before the FDA learns of such effects. ${ }^{452}$ Indeed, it is inefficient modeling for the FDA to expend limited resources in pursuit of critical information which manufacturers already possess and can readily share. ${ }^{453}$ As to an applicable standard of notification, one similar to that for pharmaceutical drugs appears sensible, at least as an initial measure. ${ }^{454}$ A preferable framework would thus require that supplement manufacturers report to the FDA all serious and unexpected adverse reactions. ${ }^{455}$

Like enhanced labeling disclosures, neither registration nor mandatory adverse event reporting would impose substantial production costs on dietary supplement manufacturers, and both would likely provide value to reputable manufacturers. ${ }^{456}$ Indeed, not only would notification of adverse event reporting inform manufacturers of reactions to similar products, it may enable them to rectify problems that might otherwise subject them to future liability. ${ }^{457}$ Equally important, these measures would not disturb consumer access to desired products; they would likely have the opposite effect, improving the quality and consistency of those desired products. Moreover, by illuminating product information for the FDA, they would diminish incentives to manipulate the market and to classify products as dietary supplements even when such products are better classifiable as foods or medicines.

Alternatively, one might consider the privilege of the continued absence of premarket testing as a tradeoff for enhanced registration and adverse event reporting. Indeed, demands for pre-market testing of dietary supplements have exploded in recent years, both on Capital $\mathrm{Hill}^{458}$ and in legal academia. ${ }^{459}$ For dietary supplement manufacturers, a compromise on relatively low-cost measures, including

451 See FDA, supra note 436 (Dr. Crawford outlining plans for the FDA to evaluate the available pharmacology, published literature (including animal, in vitro, epidemiological and clinical trial data) evidence-based reviews, and adverse event information). Id.

${ }_{452}$ See Life Sciences Research Office, supra note 334.

453 See $i d$. (noting how proposed changes in federal regulation of the dietary supplement industry have spurred some manufacturers to consider their monitoring systems).

454 Imposing a more taxing standard on dietary supplement manufacturers than on pharmaceutical drug manufacturers does not appear justified on any known evidentiary grounds. The standard's relative stringency could be revisited, however, if it were to prove insufficient in the dietary supplement setting.

${ }^{455} 21$ C.F.R. 600.80(c)(1)(i) (stating that pharmaceutical manufacturers must reveal all "serious and unexpected" adverse reactions). This would entail that whenever a supplement manufacturers learns of a serious and unexpected reaction (e.g., death, a life-threatening condition, inpatient hospitalization or prolongation of existing hospitalization) from product usage, it would immediately notify the FDA. See Michael Baram, Making Clinical Trials Safer for Human Subjects, 27 AM. J. L. \& MED. 253, 262-63 (2001) (illustrating the "serious and unexpected" standard).

456 See Colloton, supra note 163, at 549 (noting that some manufacturers complain that the FDA fails to keep them informed of adverse reactions to their products).

457 ld.

458 See, e.g., Dietary Supplement Safety Act of 2003, S. 722, 108th Cong. (2003).

459 See, e.g., Jennifer J. Spokes, Confusion in Dietary Supplement Regulation: The Sports Irony, 77 B.U. L. REv. 181 (1997); Leticia M. Diaz, First St. John's Wort, Now SAM-e: Is Society as a Whole at Risk Without FDA Regulation of Psychiatric Self-Medication?, 9 KAN. J.L. \& PUB. POL'Y 279 (1999). 
enhanced labeling, registration, and disclosure of adverse event reporting, might prove a feasible and far less burdensome outcome. ${ }^{460}$

Along these lines, required disclosure of adverse reactions was encapsulated in a recent federal legislative proposal. The Dietary Supplement Safety Act of $2003^{461}$ ("DSSA") would allow the FDA to impose the duty of postmarket surveillance on dietary supplement companies if there is a "reasonable possibility that a use or expected use of the dietary supplement by a significant number of consumers may result in serious adverse experiences." ${ }^{\text {462 }}$ However, DSSA would also amend the FDCA to require sellers of dietary supplements containing stimulants to prove the supplements' safety before sale, ${ }^{463}$ and would remove from the definition of dietary supplements those products promoting muscle growth and re-classify them as anabolic steroids. ${ }^{464}$ Demand for such pre-market safety evaluations likely explains the failure of DSSA to advance beyond its introduction. ${ }^{465}$ As emphasized in this Article, perhaps a more feasible and desirable method would focus on greater disclosure of information.

\section{CONCLUSION}

This Article does not advance a heavy-handed, paternalistic system that would prevent American consumers from purchasing dietary supplements. Nor does it discredit every dietary supplement as a product made viable by myth, ignorance, and rabid industry deceit. Rather, in recognizing the therapeutic value of many dietary supplements, as well as the intrinsic positive value of consumer choice, this Article advocates supplying consumers with useful information that the market fails to generate and thus better equipping them to make consumption decisions with diminished cognitive bias and less affecting market manipulation. This finding appears bolstered by data suggesting that a lack of information often leads to consumption of products that are more "risky" and less efficacious than consumers assume. Indeed, aligning actual risk with actual benefit would benefit any consumption choice, particularly those choices impacting the well-being of groups predisposed to discounting risk and over-estimating benefit.

460 See Steven P. Croley, Theories of Regulation: Incorporating the Administrative Process, 98 COLUM. L. REV. 1, 32 (1998) (explaining that compromises and trade-offs among competing groups can yield preferable political outcomes).

461 See S. 722, 108th Cong. (2003).

462 See Proposed Section 416(c)(2)("PERIODIC ADVERSE DIETARY SUPPLEMENT EXPERIENCE REPORTING-A manufacturer of a dietary supplement shall annually (or at such shorter intervals as the Secretary may require), in accordance with such requirements as the Secretary may establish, submit to the Secretary a report that discloses all information received with respect to adverse dietary supplement experiences ..."). Id. at $\S 416(\mathrm{c})(2)$.

463 Specifically, it would amend Chapter IV of the FDCA by adding several sections. Id.

464 Specifically, the DSSA would strike '(other than tobacco)' from the FDCA and insert "(other than tobacco or a product that bears or contains an anabolic steroid (including a substance that is chemically and pharmacologically related to testosterone but not including an estrogen, progestin, or corticosteroid)).' $I d$. at $\S 4$.

465 The dietary supplement lobby, along with various holistic medicine groups, have deftly employed fear tactics to stymie legislative progression. Indeed, consider comments by the National Nutritional Foods Association: “[DSSA] would subject nearly all vitamins, minerals, herbal products and other supplements to a level of scrutiny that is both unwarranted and unnecessary. Products that have been used safely for hundreds-and in some cases, thousands-of years would be subject to clinical evaluation using standards that are at the complete discretion of the FDA. Oppose this Legislation!" See Healing Earth Resources, The Dietary Supplement 'Safety' Act, at http://www.healingearthresources.com/site/epage/11711_163.htm (last visited, Jan. 1, 2005). 
Moreover, to the extent that an element of paternalism exists in this Article, it is carefully couched. By advocating low-cost informational mechanisms instead of product prohibition, this Article recognizes the dangers of safety regulations where the collateral risks likely outweigh the proposed risk reduction. ${ }^{466}$ At the same time, the proposals indicated in this Article would scarcely burden reputable supplement manufacturers while vastly securing industry practices, thereby diminishing the prevalence of tort liability. Accordingly, utilizing enhanced informational channels to align the interests of consumers, the FDA, and reputable supplement manufacturers appears universally beneficial.

Admittedly, the proposals in this Article should not be considered panaceas to a deeply flawed dietary supplement industry. Other, more dramatic ideas, including pre-market FDA approval and re-classification of certain supplements as drugs, may offer substantial benefit to consumers. However, these ideas also run the risk of over-bearing governmental intrusion, where the benefit of consumer safety proves outweighed by diminished consumer choice and disturbed price scheming, particularly with a pharmaceutical drug industry that already sets prices too high for many Americans. Indeed, this Article does not propose a "zero-tolerance rule" for any dietary supplement; rather, it features proposed FDA discretion that would advance flexibility and cooperation with industry. ${ }^{467}$ Similarly, by legitimizing supplements in relation to their risks and benefits, the proposals in this Article would discourage unnecessary regulatory cost and delay. At the same time, by forcing supplement manufacturers to accurately reveal benefit and risk, these proposals would presumably discourage initial investment by less reputable manufacturers, thus improving consumer confidence in remaining industry participants.

At some point in the future, more dramatic measures to protect dietary supplement consumers may prove desirable. Before contracting consumer choice, however, it appears sensible to attempt consumer enlightenment.

466 For an excellent discussion on paternalism and the drug approval process, see Michael D. Greenberg, Information, Paternalism, and Rational Decision-Making: The Balance of FDA New Drug Approval, 13 ALB. L.J. SCI. \& TECH. 663, 674-77 (2003).

467 See STEPHEN BREYER BREAKING THE VICIOUS CIRCLE: TOWARD EFFECTIVE RISK REGULATION 11 (1993) (noting that policies which encourage automatic removal of asbestos from buildings-regardless of the amount of asbestos-can cause more damage than asbestos itself). 